\title{
Who Can I Count On: Honor and Self-Reliance During the COVID-19 Pandemic
}

\author{
Peter Wang, ${ }^{a}$ Mohammad Atari, ${ }^{a}$ and Daphna Oyserman ${ }^{\mathrm{a}}$ \\ ${ }^{a}$ Department of Psychology, University of Southern California \\ 3620 S. McClintock Ave., SGM 501, Los Angeles, CA, 90089
}

Email:

PeterWang, peterpwa@usc.edu

Mohammad Atari, atari@usc.edu

Daphna Oyserman,oyserman@usc.edu

Correspondence concerning this article should be addressed to Peter Wang, Dept. of Psychology, 3620 S. McClintock Ave., SGM 501, Los Angeles, CA, 90089. Email: peterpwa@usc.edu or to Daphna Oyserman, Dept. of Psychology, 3620 S. McClintock Ave., SGM 501, Los Angeles, CA, 90089. Email: oyserman@usc.edu

Funding: This work was supported by the Mind and Society Center, University of Southern California, Los Angeles, CA, and the Department of Psychology, University of Southern California, Los Angeles, CA. 


\begin{abstract}
During the COVID-19 pandemic, people differed in how much they took matters into their own hands rather than follow COVID-19-related public health guidelines. In this paper, we take a culture-as-situated cognition perspective to suggest that one reason for this variability may be that the pandemic triggered honor concerns. Honor is a cultural mindset focused on protecting oneself and one's family by maintaining reputation. To demonstrate honor, people may take matters into their own hands when this is possible. During the pandemic, Americans, recruited on Prolific, (Studies 1, 2) who valued honor acted independently of governmental measures because they preferred relying on themselves $(\mathrm{N}=1,179)$. This was not the case for Iranians, recruited through social media, (Study 3), for whom higher honor values predicted increased adherence to public health guidelines. Our results imply that how demonstrating honor values translates to action depends on contextual features that affect how people construe self-reliance. Keywords: Cultural Psychology, Honor, Self-Reliance, Trust in Government, COVID-19 Pandemic, Culture, Public Health.
\end{abstract}




\section{Who Can I Count On: Honor and Self-Reliance During the COVID-19 Pandemic}

\section{Introduction}

The death toll and economic hardships caused by the COVID-19 pandemic combine with the novelty of the threat to make it one of the most socially disruptive events in recent human history. People across the world reported more anxiety and stress and lower well-being (Chen et al., 2021). The scope of the pandemic overwhelmed many governments and left people deciding whether to try fending for themselves or trust their governmental institutions to secure their safety and well-being. People who were unsure about whether they could rely on their government were at risk of ignoring or rejecting COVID-19 public health guidelines (Chan et al., 2020; Fletcher et al., 2020) while accepting or acting on unofficial, potentially false, advice (Calvillo et al., 2020; Simonov et al., 2020). As a result, people might refuse to wear face masks (Chan, 2020), fail to socially distance (Chan, 2020), or hoard consumer goods (Baddeley, 2020). Understanding factors associated with cooperation with government guidelines is important because local incidence of COVID-19 was higher in communities with less adherence to these public health guidelines (Alagoz et al., 2021). In this paper, we build on culture-as-situated cognition theory to consider the situated impact of one such factor, endorsing an honor mindset.

Culture-as-situated cognition theory predicts that human culture evolved within ecologies as a "good enough" solution to basic problems of survival: since people need others to survive, groups need to be sustained over time and need to organize interactions to reduce conflict while facilitating individual welfare (Oyserman, 2011, 2017). Sustaining the group implies sensitivity to issues of group membership, fitting in, and belonging, termed collectivistic mindset; organizing interactions implies sensitivity to reputation, loyalty to family and other groups, and willingness to protect them, termed honor mindset. Facilitating individual welfare implies 
sensitivity to individual needs, desires, and preferences, termed individualistic mindset. Each of these cultural mindsets can be understood as a set of mental representations or cognitive schemas containing relevant mental content, cognitive procedures, and goals (Oyserman, 2017). Cultureas-situated cognition theory predicts that each of these cultural mindsets (collectivism, honor, individualism) is part of human culture, that each society develops within a particular niche, and that chronic and more situated features of niches matter by affecting which cultural mindset is on the mind and how it is expressed (Oyserman, 2017). Indeed, researchers have examined both society-specific and society-general ways in which honor values, such as family pride and reciprocity, are instantiated (e.g., Cross et al., 2014; Leung \& Cohen, 2011; Uskul et al., 2010).

\section{Honor and Responses to COVID-19}

Evolutionary accounts of honor have found a link from socioecological factors to cultural phenotypes of honor (Cao et al., 2021; Nowak et al., 2016; Shackelford, 2005). Specifically, in a pastoral environment, an individual's standing, especially economic standing, is directly related to livestock which is vulnerable to theft. Pastoral environments often lack any sources of central legal enforcement. Vulnerability to theft and lack of a central governing body have been theorized to favor a suite of psychological phenotypes characteristic of honor cultures. McElreath (2003) tested this theory, formally demonstrating that reputational effects can have a crucial influence on fitness under these conditions. McElreath (2003) concluded that reputationbased strategies may result in greater willingness to fight depending on the nature of the contests and the local socio-ecological conditions.

Moreover, cultural psychologists have argued that honor is a cultural mindset which focuses people on protecting their well-being and that of their families or larger groups (Cohen et al., 1996; Oyserman, 2017). To accomplish this, honor-minded people are motivated to defend 
their reputation so that others will be less likely to take advantage of them. Historically, honor culture emerged in niches in which central authorities were unreliable (Cohen \& Nisbett, 1997) or even absent (see Nowak et al., 2016; Shackelford, 2005), and resources scarce (Uskul \& Cross, 2020). Lacking institutional safeguards, people needed a means to reduce the chances that others might try to exploit or attack them or appropriate their resources. In interpersonal interactions, honor marking, highlighting one's vigilance towards reputation and slights against it, provides a way for people to deter others who might exploit them, their families, or groups (Leung \& Cohen, 2011). Indeed, people who have honor concerns are more likely to respond aggressively to norm violations such as insults (e.g., Cohen et al., 1996; Flinkenflogel et al., 2020). This allows them to show that they can fend for themselves, making potential offenders less likely to target them.

The COVID-19 pandemic produced circumstances matching these historical conditions. Central authorities could be perceived as unreliable as the novelty of the pandemic made it difficult for governments to address problems effectively and resulted in changing recommendations as their knowledge increased. No one yet knew how the virus spread, how to treat it, or how to prevent it. As the pandemic expanded, people felt that even basic resources were scarce (Civai et al., 2021; Islam et al., 2021), and many national governments struggled to contain its social, economic, and epidemiological fallout. We predicted that the pandemic could trigger honor-based reasoning of the kind: If the government cannot look out for me, I must look out for myself. Specifically, as depicted in Figure 1, we predict that honor concerns may lead people to act independently of government directives, adhere less to government COVID-19 instructions because they prefer to rely on themselves. One might wonder at the seeming paradox that people who care deeply about protecting themselves and their families would reject 
government efforts to keep them safe. We made this prediction because the pandemic created multiple threats to economic livelihood and civil liberties as well as uncertainty as to how to handle health-related threat in the context of these other threats. Given changing guidelines, conforming to government COVID-19 regulations could imply dependency on an unreliable government and an inability to fend for oneself, prospects that conflict with honor-based protection concerns. ${ }^{1}$ While tendencies to defy COVID-19 regulations might vary from country to country, there is evidence that at least people in the U.S. saw some government measures, such as mask mandates, as dangerous and in conflict with other values (Lee, 2021). Moreover, former President Donald Trump himself obstructed government efforts to enforce COVID-19 regulation (Haberman, 2020; Johnson, 2020), aligning himself with antigovernment values and emboldening groups that distrusted government. In our studies, we explore the possibility that distrust of government amplifies the relationships between honor, self-reliance, independent action, and adherence to public health guidelines.

We operationalize honor-relevant self-reliance as a tendency to follow one's own ideas and beliefs as opposed to depending on the government. In the context of honor, self-reliance implies an aversion to depending on government instructions, eschewing expressions of compliance. Unlike reactance (Brehm, 1989), this does not mean doing the opposite but rather an aversion to depending on government recommendations. Being told that masks are unnecessary or even potentially harmful (as was the case in the U.S. at the beginning of the pandemic) is not a matter of dependence on government, but being told to wear a face mask and complying signifies that one needs government assistance to protect oneself and one's family. Hence, we expect that

\footnotetext{
${ }^{1}$ In March of 2020, the Centers for Disease Control (CDC) instructed the public not to wear face masks; in April, the CDC asked the public to wear masks. What a good-enough mask entailed also changed over time.
} 
people who care about honor would flaunt those CDC guidelines about acts of commission (e.g., stay home, wear a mask, social distance) but not about acts of omission (e.g., no need to wear a mask).

Figure 1

Theoretical Process Model

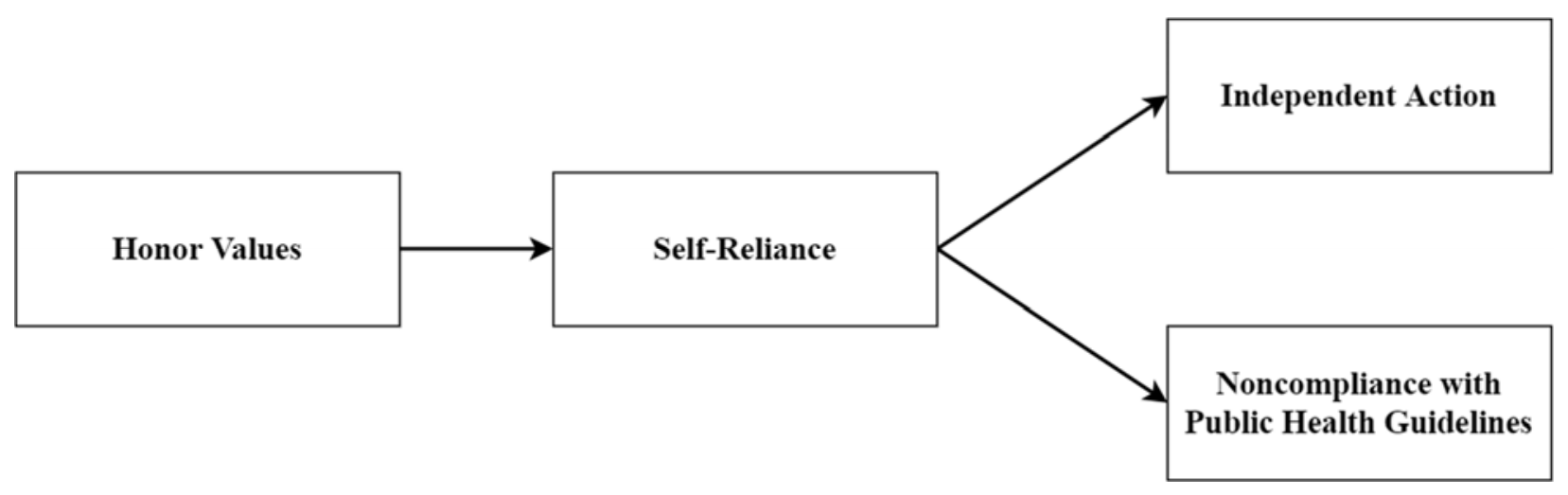

\subsection{Theoretical Contribution of the Current Studies}

We graphically display our theoretical process model in Figure 1. Our framework is congruent with descriptive reports of American honor culture (e.g., Vance, 2016) and with work by Schiffer and colleagues (2021). They report that Americans who endorse honor-related beliefs about masculinity express a greater preference for individual freedom, favor reopening the economy over protecting public health, and tend to oppose social distancing (Schiffer, et al., 2021). These results support our predictions but do not directly test them. First, they measured a narrower, gendered version of honor-related beliefs. Second, they did not measure attitudes toward self-reliance. Third, they only used American samples.

We did not find direct tests or theoretical predictions addressing whether the link between honor and self-reliance varies by region (e.g., Leung \& Cohen, 2011). However, a culture-assituated-cognition approach highlights the need to test whether honor always relates to self- 
reliance, independent action, and compliance with public health guidelines in the same ways. One possibility is that honor increases focus on self-reliance generally. That is, across societies and ecological niches, people who care about honor want to show that they can fend for themselves and will therefore ignore pandemic directives. Another possibility is that people in different societies will express honor differently depending on their ecological niche.

Consider for example, how honor may operate within an American socio-cultural niche. Americans have historically focused on liberty and opposed government regulation (Bazzi et al., 2020). During the first year of the pandemic, the Trump administration trivialized the COVID-19 pandemic and the role of government in regulating it (Holland \& Alper, 2020). Together, these public announcements may have led Americans to interpret cooperation with pandemic directives as cowardly and conformist, incompatible with the reputational values of honor. Hence, Americans might have perceived reliance on government as antithetical to honor. People in societies who are not exposed to these frames might not share that perception. As our contrast to the U.S., we focus on Iran, a Muslim-majority society with strong honor norms in which honor concerns may be chronically accessible (Ashayeri \& Ajami, 2015; Razavi et al., 2020). In both countries, the COVID-19 pandemic increased stress and anxiety about health and well-being (Chen et al, 2021) and undermined public trust in government (in the U.S., Deslatte, 2020; in Iran, Harris, 2020). At the same time, the structure of government and political tenor of the U.S. and Iran are considerably different and their societies organize moral values differently (Atari et al., 2020). In Iran, international sanctions imposed by the U.S. have led to a deep economic recession (Murphy et al., 2020), a steep increase in the cost of basic goods (Kokabisaghi, 2018), and once these became available elsewhere, blocked access to COVID-19 vaccines (Reuters Staff, 2020). Poor economic conditions impede access to 
healthcare (Aloosh et al., 2019) and COVID-19 treatment (Murphy et al., 2020). Self-reliance may not be a viable option for people who lack access to healthcare and consumer goods. Instead, Iranians may rely on their communities for mutual aid and cooperation. Under these conditions, self-reliance conflicts with the protective function of honor for family reputational, economic, and health needs. Furthermore, Iranians may not moralize government regulation in the same way as Americans. Without a cultural context that disparages dependence on government, Iranians who value honor may not interpret cooperation with government as demeaning.

To test these competing accounts and address the generalizability of our predictions, we compare results from the U.S. and Iran. We hope that our comparative approach and our focus on how honor relates to interactions between citizens and their governments will broaden our understanding of honor beyond prior research on interpersonal exchanges. Moreover, since Iran is generally an understudied, hard-to-reach population (Atari et al., 2021), adding knowledge about Iranian honor and cooperation with government is particularly important in the context of the COVID-19 pandemic (Rosenfeld et al., 2021).

\section{Current Studies}

We test four hypotheses derived from our theoretical process model in the U.S. (Studies 1, 2) and Iran (Study 3) during the COVID-19 pandemic.

H1: People who endorse honor values will show greater preference for self-reliance.

H2: People's preference for self-reliance will mediate the relationship between their endorsement of honor values and willingness to take independent action. 
H3: People who endorse honor values will especially prefer self-reliance when they also distrust government (distrust moderates the relationship between honor and self-reliance).

H4: People's preference for self-reliance will mediate the relationship between their endorsement of honor values and willingness to adhere to public health guidelines.

We collected our data for Studies 1, 2, and 3 as the pandemic continued to spread. In Figures 2 and 3, we pinpoint our data collection relative to the spread of COVID-19 (for COVID-19 cases data see Dong et al., 2020; Ritchie et al., 2020). All our measures are in our Supplemental Materials, and our data and analysis syntax are at OSF (Open Science Framework; https://osf.io/m4sfn/?view_only=1f0d84a5426e4297b1292e3824b66941).

Our studies met the ethical guidelines of the [redacted] Institutional Review Board and were approved as exempt for presenting minimal risk to participants.

\section{Figure 2}

Timeline of Data Collection and New COVID-19 Cases in the U.S. (Studies 1 and 2) 


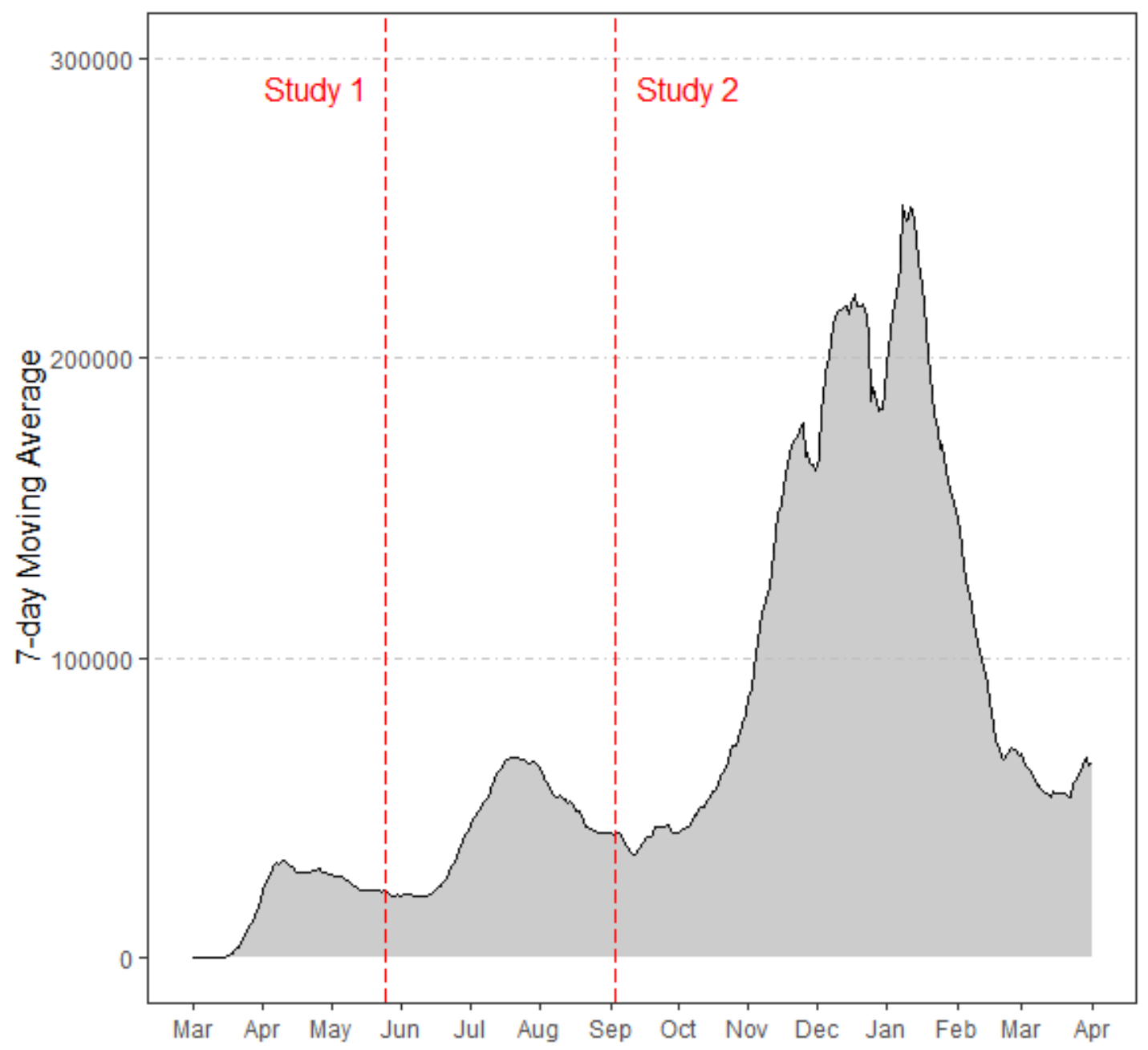

Note. The y-axis represents the 7-day moving average of new COVID-19 cases in the U.S. The red lines indicate when data collection for Studies 1 and 2 began.

\section{Figure 3}

Timeline of Data Collection and New COVID-19 Cases in Iran (Study 3) 


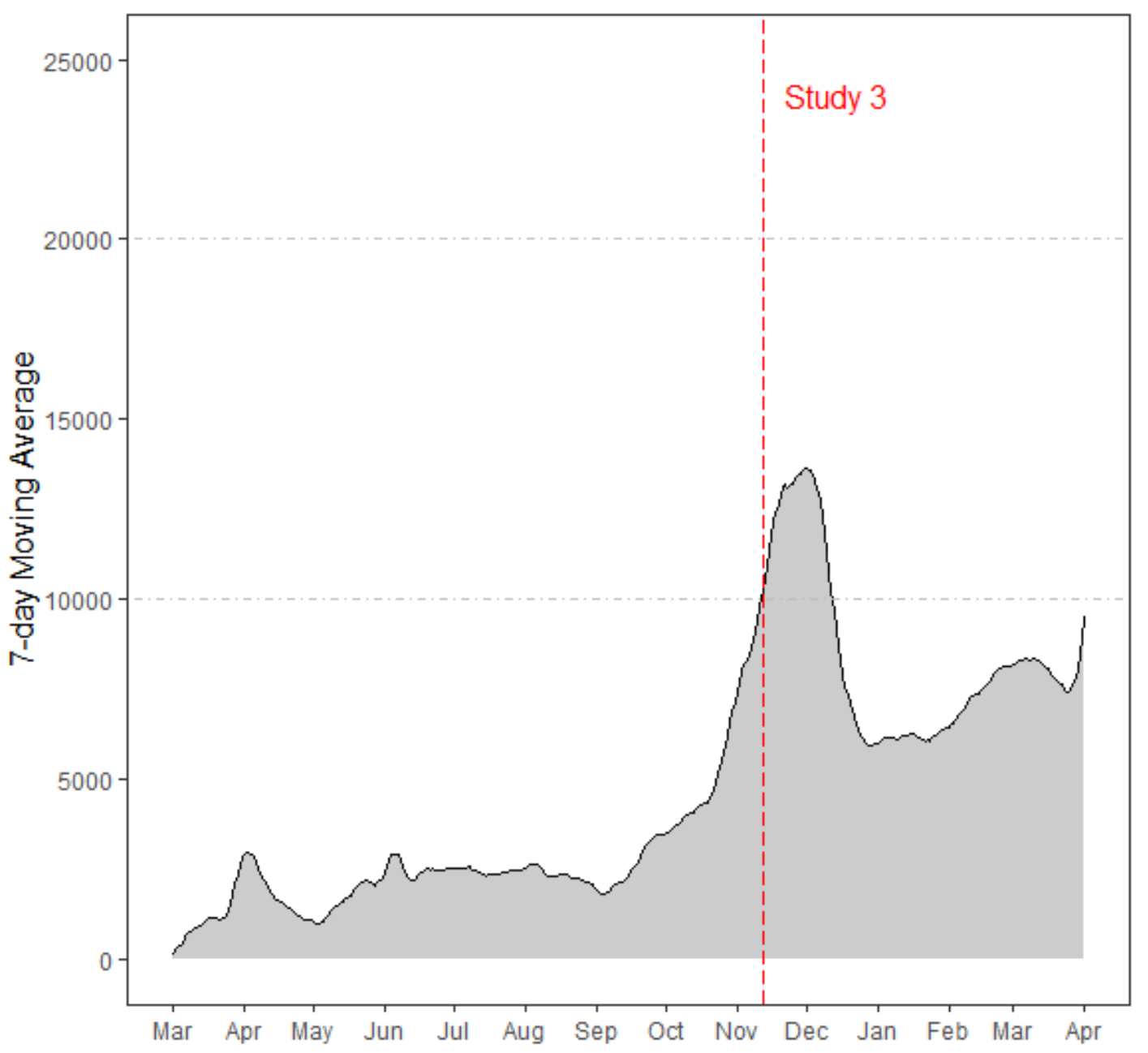

Note. The y-axis represents the 7-day moving average of new COVID-19 cases in Iran. The red line indicates when data collection for Study 3 began.

\subsection{Study 1}

In Study 1, we tested the role of honor values in promoting self-reliance and independent action, and whether government distrust moderates this relationship.

\section{Table 1}

Studies 1, 2, and 3: Sample Descriptions 


\section{Study 1 (U.S.) Study 2 (U.S.) $\quad$ Study 3 (Iran)}

\begin{tabular}{|c|c|c|c|}
\hline Sample Size $n$ & 392 & 586 & 201 \\
\hline Gender & $\begin{array}{l}42.86 \% \text { female, } 55.36 \% \\
\text { male, } 1.53 \% \text { other, } \\
0.26 \% \text { no response }\end{array}$ & $\begin{array}{l}54.95 \% \text { female, } 43.69 \% \\
\text { male, } 1.37 \% \text { other }\end{array}$ & $\begin{array}{l}69.20 \% \text { female, } \\
30.80 \% \text { male }^{\mathrm{a}}\end{array}$ \\
\hline Age in Years & $\begin{array}{l}M=30.27, S D=10.31 \\
\text { range } 18-68\end{array}$ & $\begin{array}{l}M=32.27, S D=12.86, \\
\text { range } 18-77\end{array}$ & $\begin{array}{l}M=34.94, S D=8.32, \\
\text { range } 19-61\end{array}$ \\
\hline $\begin{array}{l}\text { Race-Ethnicity } \\
\text { (multiple selections } \\
\text { allowed) }\end{array}$ & $\begin{array}{l}75.26 \% \\
\text { Caucasian/White, } \\
15.56 \% \text { Asian/Asian- } \\
\text { American, } 8.93 \% \\
\text { Hispanic/Latino, } \\
7.40 \% \text { Black/African } \\
\text { American, } 2.55 \% \text { Native } \\
\text { American or Alaska } \\
\text { Native, } \\
0.51 \% \text { Middle Eastern, } \\
0.26 \% \text { Hawaiian Native } \\
\text { or Pacific Islander, } \\
1.02 \% \text { Other }\end{array}$ & $\begin{array}{l}70.48 \% \\
\text { Caucasian/White, } \\
17.75 \% \text { Asian/Asian- } \\
\text { American, } 8.53 \% \\
\text { Hispanic/Latino, } \\
6.83 \% \text { Black/African } \\
\text { American, } \\
1.88 \% \text { Native American } \\
\text { or Alaska Native, } \\
1.54 \% \text { Middle Eastern, } \\
0.51 \% \text { Hawaiian Native } \\
\text { or Pacific Islander, } \\
0.51 \% \text { Other }\end{array}$ & $\begin{array}{l}100 \% \text { Iranian/Persian, } \\
\text { first language Farsi }\end{array}$ \\
\hline $\begin{array}{l}\text { Political } \\
\text { Orientation }\end{array}$ & $\begin{array}{l}M=3.032, S D=1.445 \\
1=\text { Very Liberal to } 7= \\
\text { Very Conservative }\end{array}$ & $\begin{array}{l}M=2.984, S D=1.578 \\
1=\text { Very Liberal to } 7= \\
\text { Very Conservative }\end{array}$ & $\begin{array}{l}85.07 \% \text { left-leaning, } \\
14.93 \% \text { right-leaning }\end{array}$ \\
\hline
\end{tabular}

Note. Study $1 n=402$ before excluding 10 participants for failing attention check. Study $2 n=$

617 before excluding 27 participants for failing attention check, 3 for incomplete scales, and 1 for being under 18 .

a, basked as a binary (male, female; left-leaning, right-leaning).

\subsubsection{Methods}

3.1.1.1. Participants. We conducted an a priori power analysis in $\mathrm{G}^{*}$ Power 3.1.9.2 (Faul et al., 2009) for a linear regression predicting self-reliance from honor values. Since prior work has not examined this relationship, we set a small-to-medium effect size (partial $R^{2}=0.03$ ), based on guidelines provided by Cohen (1988) in which an $R^{2}$ of 0.01 is small and 0.09 is medium. We found that 342 participants would be required to find an $R^{2}$ increase at $85 \%$ power, with an alpha of 0.05 . We aimed to recruit 400 participants to account for possible data loss and 
attention check failures, recruiting 402 U.S. participants on Prolific during the last week of May 2020. Inclusion criteria were being of U.S. nationality, currently residing in the U.S., being fluent in English, and having a 90\% or higher approval rate. We excluded 10 participants who failed the attention check, resulting in a final sample for analyses of 392 participants (see Table 1 for sample description).

3.1.1.2. Measures and Procedure. We used the same 7-point $(1=$ Strongly Disagree to 7 = Strongly Agree) response option set for all of our scales (honor values, self-reliance, COVID19 behavior, and government distrust). We detail descriptive statistics and internal consistency coefficients for each scale, as well as the correlations between our scales, in Table 2. Given that the adherence to guidelines scale only has 2 items, the reliability coefficient for the scale is small - such scales tend to have low reliability coefficients (see Eisinga et al., 2013). We detail additional measures included for secondary and exploratory analyses and the order of measures in Supplemental Materials.

3.1.1.2.1. Honor Values Scale (HVS). We used Novin and Oyserman's (2016) 18-item Honor Values Scale (HVS; sample item: "Reputation matters and should be vigorously defended.’')

3.1.1.2.2. Self-Reliance. We created a 4-item pandemic self-reliance scale (e.g., "During this pandemic, instead of relying on official sources, I should trust myself.").

3.1.1.2.3. COVID-19 Behavior (Independent Action and Public Health Adherence). We created a 10-item scale of responses to the pandemic, including actions that ignore government recommendations (e.g., "stockpile household cleaners and food") and ones that adhere to CDC public health guidelines (e.g., "stay at home for as long as possible"). Preliminary analyses presented below (section 3.1.2.1) led us to drop 3 items from the scale and analyze the scale 
through two subscores: independent action ( 5 items; acting independently of government) and public health adherence ( 2 items).

3.1.1.2.4. Government Distrust. We created a 5-item scale measuring endorsement of narratives associated with government distrust in the context of COVID-19 (e.g., "During this pandemic, the government can't be trusted to protect businesses from economic damage").

3.1.1.2.5. Political Orientation. Participants reported their political orientation in social and economic domains $(1=$ Very Liberal to $7=$ Very Conservative $)$.

Table 2

Study 1: Means, Standard Deviations, Cronbach's Alphas, and Correlations for Key Variables

\begin{tabular}{lccccccc}
\multicolumn{1}{c}{ Measure } & $\begin{array}{c}\text { Descriptive } \\
\text { Statistics }\end{array}$ & $\alpha$ & \multicolumn{5}{c}{ Pearson's Correlations } \\
& $M(S D)$ & & 1 & 2 & 3 & 4 & 5 \\
\hline 1. Honor Values & $4.64(0.80)$ & .86 & 1.00 & & & & \\
2. Government Distrust & $4.74(1.23)$ & .82 & .07 & 1.00 & & & \\
3. Self-Reliance & $4.67(1.52)$ & .91 & $.40^{* * *}$ & $.12^{*}$ & 1.00 & & \\
4. Independent Action & $3.89(1.20)$ & .72 & $.18^{* * *}$ & .09 & $.36^{* * *}$ & 1.00 & \\
5. Adherence to & $5.92(1.04)$ & .53 & -.04 & .05 & $-.20^{* * *}$ & .01 & 1.00 \\
Guidelines & & & & & & &
\end{tabular}

Note. Correlation coefficients represent Pearson's $r$.

$* p<.05, * * p<.01, * * * p<.001$

\subsubsection{Results}

3.1.2.1. Preliminary Analyses. We examined skewness and variability in the items from our measures and conducted factor analyses. We dropped two items from the initial pool of COVID-19 behaviors ("attend protests" and "ignore distancing requirements") due to low variability and high skewness, and a third item ("take on new sources of income") due to low factor loadings. Factors corresponded to our intended constructs: self-reliance, government distrust, public health adherence, and independent action. We present details of our factor analyses in Supplemental Materials. 
For exploratory purposes, we used independent samples t-tests to examine within-country variation on our 5 key variables (honor, government distrust, self-reliance, public health adherence, and independent action). We found no differences on mean endorsement of any of these variables between the U.S. South (boundaries defined by Cohen et al., 1996) and the rest of the U.S., or between states that voted for the Republican nominee ("red" states) and states that voted for the Democratic nominee ("blue" states) based on results from 2004, 2008, 2012, and 2016 presidential elections. We present detailed results from these t-tests in Supplemental Materials. Given that we did not find regional or election-based differences in endorsement of honor values we do not use these constructs in further analyses (see also Novin \& Oyserman, 2016).

3.1.2.2. H1: Honor is Associated with Self-Reliance. We ran a linear regression predicting self-reliance from honor values. Results support our prediction, as detailed in Table 3 (top panel). People who scored higher in honor values indicated greater preference for selfreliance, $\beta=0.40, p<.001$.

Table 3

Study 1 (H1, H3): Results of Linear Regressions Predicting Self-Reliance

\begin{tabular}{|c|c|c|c|c|c|c|c|c|}
\hline \multirow[t]{2}{*}{ Variable } & \multicolumn{8}{|c|}{ Statistics } \\
\hline & $\begin{array}{c}\beta \\
95 \% \mathrm{CI} \\
{[\mathrm{LL}, \mathrm{UL}]}\end{array}$ & $S E$ & $t$ & $p$ & $\begin{array}{l}\text { Adjusted partial } \\
\qquad R^{2}\end{array}$ & $F$ & $d f$ & $\begin{array}{l}\text { Adjusted } \\
R^{2}\end{array}$ \\
\hline \multicolumn{9}{|c|}{ Model H1 } \\
\hline Honor Values & $\begin{array}{c}0.40 \\
{[0.31,0.49]}\end{array}$ & 0.05 & 8.54 & $<.001$ & 0.16 & 72.93 & 390 & 0.16 \\
\hline \multicolumn{9}{|c|}{ Model H3 } \\
\hline Honor Values & $\begin{array}{c}0.38 \\
{[0.29,0.47]}\end{array}$ & 0.05 & 8.20 & $<.001$ & 0.15 & 28.41 & 388 & 0.17 \\
\hline $\begin{array}{l}\text { Government } \\
\text { Distrust }\end{array}$ & $\begin{array}{c}0.09 \\
{[-0.00,0.18]}\end{array}$ & 0.05 & 1.96 & .051 & 0.01 & & & \\
\hline
\end{tabular}




$\begin{array}{cccccc}\begin{array}{c}\text { Honor Values } \times \\ \text { Government } \\ \text { Distrust }\end{array} & 0.11 & 0.04 & 2.59 & .010 & 0.01 \\ & {[0.03,0.20]} & & & & \end{array}$

Note. H1: Honor values and self-reliance. H3: Moderation of honor values by government distrust in predicting self-reliance.

\subsubsection{H2: Self-Reliance Mediates the Relationship between Honor and}

Independent Action. As we detailed in Table 2, independent action correlated positively with both honor concerns, $r=.18, p<.001$, and self-reliance, $r=.36, p<.001$, allowing us to test the mediation we predicted in $\mathrm{H} 2$. We ran a mediation model with paths from honor values to selfreliance to independent action. Supporting our prediction, we found an indirect effect of honor values on independent action through self-reliance, $\beta=0.13,95 \%$ CI $[0.09,0.19]$ (bootstrapped 5000 times), mediation effect $R^{2}=0.031$ (for calculation of mediation effect $R^{2}$, see Fairchild et al., 2009). Participants' endorsement of honor values was no longer related to their willingness to take independent action after accounting for their preferences for self-reliance, $\beta=0.08, p=$ .135. This mediating effect was robust, remaining significant even when we added gender and political orientation as control variables (see Supplemental Materials).

Since our data were collected cross-sectionally, we conducted an alternate mediation with paths from honor values to independent action to self-reliance (see Agler \& De Boeck, 2017). The indirect effect of honor in this direction was significant but smaller, $\beta=0.05,95 \% \mathrm{CI}[0.02$, 0.09] (bootstrapped 5000 times).

\subsubsection{H3: Government Distrust Moderates the Relationship between Honor and}

Self-Reliance. We ran a linear regression to test the moderating effect of honor values and government distrust on self-reliance. Supporting our prediction, self-reliance was more strongly related to honor among participants with higher distrust of government (see Figure 4 and Table 3 
bottom panel), $\beta=0.11, p=.010$. We added government distrust as a moderator of the honor values and self-reliance relationship in the $\mathrm{H} 2$ mediation model (Figure 5), finding a moderated mediation, $\beta=0.04,95 \% \mathrm{CI}[0.00,0.08]$ (bootstrapped 5000 times). We examined the indirect effect of honor separately for high distrust (1 SD or higher above mean government distrust) and low distrust participants (1 SD or lower below mean government distrust). Supporting our prediction, the indirect effect was significant among high-distrust, $\beta=0.15,95 \% \mathrm{CI}[0.03,0.26]$, but not low-distrust participants, $\beta=0.01,95 \%$ CI $[-0.06,0.10]$.

We conducted an alternate mediation with paths to independent action and then selfreliance. The moderated mediation was not significant, $\beta=0.02,95 \% \mathrm{CI}[-0.01,0.06]$ (bootstrapped 5000 times).

\section{Figure 4}

Study 1 (H3): The Interaction of Honor Values and Government Distrust Predicting SelfReliance 


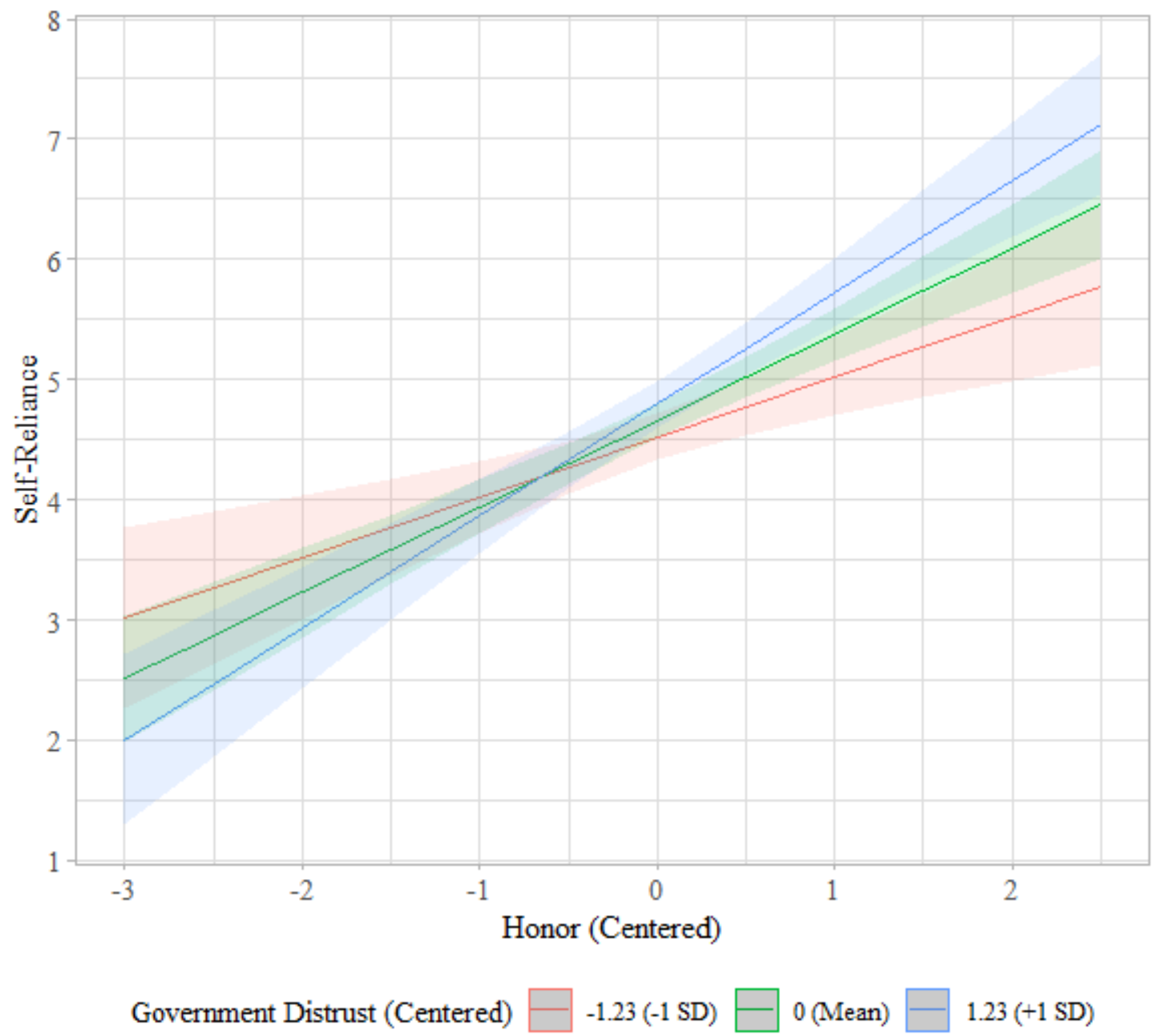

Figure 5

Study 1 (H2): Self-Reliance as Mediator Between Honor and Independent Action, Moderated by Government Distrust 


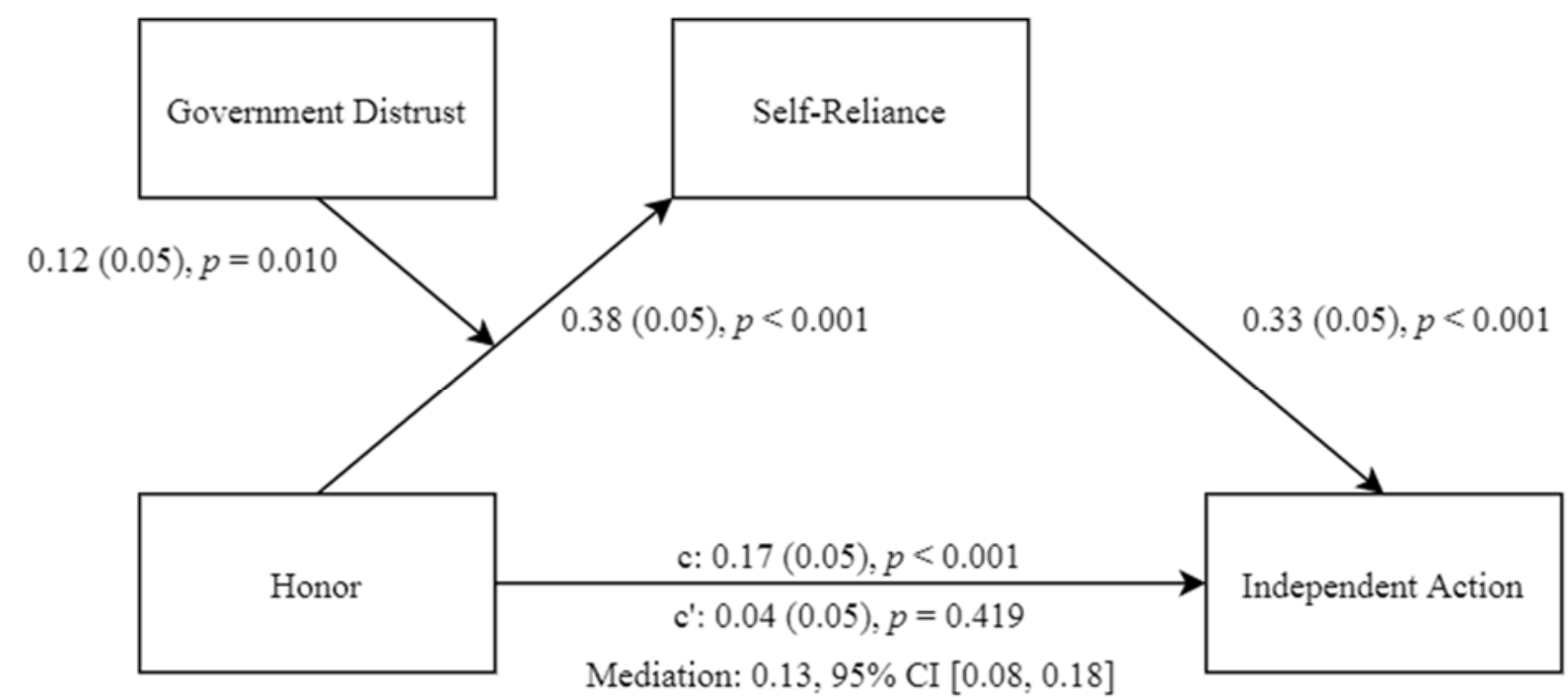

Moderated mediation: $0.04,95 \% \mathrm{CI}[0.00,0.08]$

Note. A comprehensive model of our Study 1 results. Standard errors are inside the parentheses.

\subsubsection{H4: Self-Reliance Mediates the Relationship between Honor and Public}

Health Adherence. As detailed in Table 2, public health adherence was negatively correlated with self-reliance, $r=-.20, p<.001$, but was not correlated with honor, $r=-.04, p=.449$. However, our mediation model with paths drawn from honor to self-reliance to public health adherence (see Figure 6) revealed a significant indirect effect of honor on public health adherence through self-reliance, $\beta=-0.09,95 \%$ CI $[-0.13,-0.04]$ (bootstrapped 5000 times). We found that greater honor endorsement was associated with greater preference for self-reliance, which in turn was associated with lower adherence. An alternate model with paths from honor to adherence to self-reliance revealed no significant mediation, $\beta=0.01,95 \% \mathrm{CI}[-0.01,0.03]$ (bootstrapped 5000 times).

We then added government distrust as a moderator of the relationship between honor and self-reliance in the mediation model. We found a significant indirect effect of the interaction term, $\beta=-0.03,95 \%$ CI $[-0.06,-0.00]$ (bootstrapped 5000 times). We then examined the indirect effect of honor separately for participants with high distrust (1 SD or higher above mean 
government distrust) and participants with low distrust (1 SD or lower below mean government distrust). Consistent with our prediction, the indirect effect was significant among high-distrust participants, $\beta=-0.19,95 \%$ CI $[-0.31,-0.09]$, but not low-distrust participants, $\beta=-0.00,95 \% \mathrm{CI}$ $[-0.07,0.06]$. An alternate model with paths to adherence and then self-reliance revealed no significant moderated mediation, $\beta=0.02,95 \%$ CI $[-0.01,0.06]$ (bootstrapped 5000 times).

\section{Figure 6}

Study 1 (H4): Mediation of Honor and Adherence to Public Health Guidelines by Self-Reliance

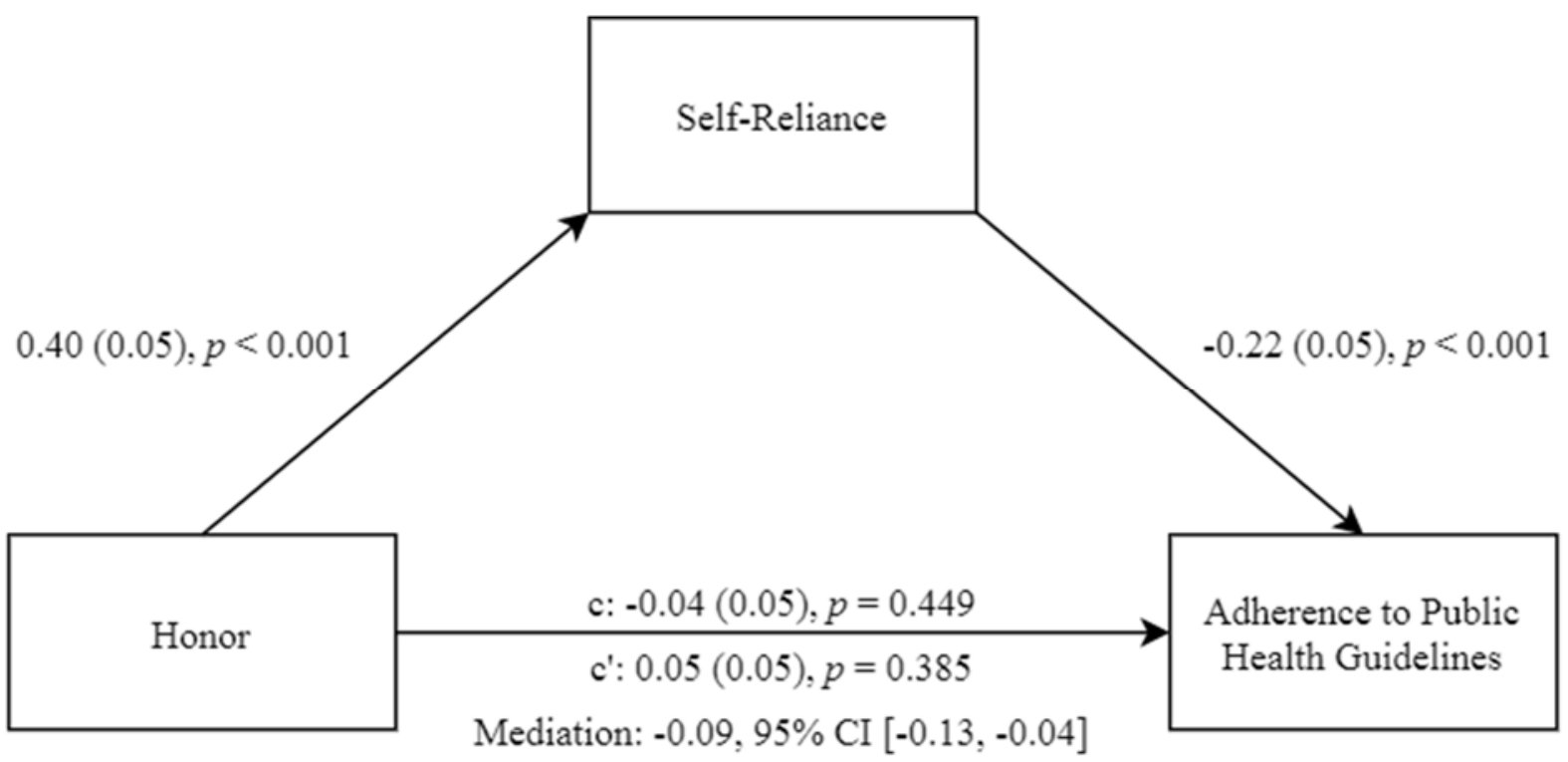

Note. Values inside the parentheses indicate standard errors.

\subsubsection{Discussion}

We found support for $\mathrm{H} 1$ to H4. Americans who cared more about honor values were more willing to rely on themselves (H1) and act independently of government recommendations, and this preference for self-reliance explained the association between honor and independent action (H2). The mediating effect was significant but smaller in an alternate model with paths 
from honor to independent action to self-reliance, suggesting that we cannot rule out this possibility. Americans who cared more about honor were especially willing to rely on themselves when they also distrusted the government (H3). While we did not find a direct effect of honor on public health adherence, we found an indirect effect of honor on adherence through self-reliance (H4). There was no indirect effect in the alternate model with paths from honor to adherence to self-reliance, increasing our confidence in the predicted direction of mediation. Americans who cared more about honor were more willing to rely on themselves, and because of this preference, they were less willing to adhere to CDC-issued public health guidelines. This finding provides converging evidence that honor can impede cooperation with the government and willingness to follow public health guidelines during the COVID-19 pandemic. Study 1 results broadly suggest that Americans with stronger honor values prefer to rely more on themselves, taking actions separately from government-issued guidance in the context of COVID-19. Note that two relevant correlations between honor and independent action, and between self-reliance and government distrust are small but significant. This small effect implies that other factors also matter and certainly our focus on honor does not imply that other factors might not also be at play. As we noted above, we explored but did not find regional variations based on geography or pattern of Presidential voting for our variables of interest; hence we focused on individual-level variables in Study 1.

\subsection{Study 2}

In Study 2, we tested the stability of the relationships we found in Study 1 in the U.S. as 
the pandemic continued to spread. ${ }^{2}$

\subsubsection{Methods}

3.2.1.1. Participants. We aimed to collect 615 participants based on our a priori G*Power 3.1.9.2 power analysis for our smallest Study 1 effect size (honor-by-governmentdistrust interaction, partial adjusted $R^{2}=0.014$ ). For that interaction in a multiple linear regression with 3 predictors, we would need 614 participants to find an $R^{2}$ increase at $85 \%$ power. We recruited 617 U.S. adults on Prolific during the first week of September 2020. Inclusion criteria were being of U.S. nationality, currently residing in the U.S., being fluent in English, having an approval rate of $90 \%$ or higher, and not having participated in Study 1 . Our final sample $(n=586)$ for analyses excluded people who failed the attention check, skipped key scales, or said were under 18 (Table 1 for sample description).

3.2.1.2. Measures and Procedure. We kept the HVS and self-reliance scale constant from Study 1. We detail descriptive statistics, internal consistency coefficients, and correlations among the study measures in Table 4. Order of measures and additional measures included for exploratory and secondary analyses are detailed in Supplemental Materials.

3.2.1.2.1. Independent Action. Given the rapid changes in the pandemic and that we would conduct a study in Iran, we created a 6-item scale, revising Study 1 items so that, instead of specific behaviors that could become outdated, items described general-response patterns (e.g., "I should seek out protections that make sense to me, no matter what the government says." $1=$ Strongly Disagree, 7 = Strongly Agree)

\footnotetext{
${ }^{2}$ We wrote the pre-registration for Study 2 on August 19, 2020, before data collection. However, due to researcher error, our pre-registration was not submitted to AsPredicted.org until September 5, shortly after data collection ended on September 4, but before any data analyses (https://aspredicted.org/blind.php? $\mathrm{x}=\mathrm{vv7gi8)}$.
} 
3.2.1.2.2. Government Distrust. Emerging civil liberties concerns when we designed and conducted Study 2 (August, September 2020) led us to add a new item to the distrust scale on the government's inability to "restrain itself from infringing on the rights of individuals." However, the item showed poor fit with the rest of the scale in the U.S. sample (see Supplemental Materials), so we excluded it from further analyses.

3.2.1.2.3. Public Health Adherence. Given that many people were required to work inperson during the pandemic, we added the item: "During the pandemic, I should try to convince my loved ones to stay home as much as possible." This would allow participants to report their attitudes towards staying at home without having to consider whether they were able to stay at home or not.

\section{Table 4}

Studies 2 and 3: Means, Standard Deviations, Cronbach's Alphas, and Correlations for Key Variables

\begin{tabular}{|c|c|c|c|c|c|c|c|}
\hline \multirow[t]{2}{*}{ Measure } & \multirow{2}{*}{$\begin{array}{c}\text { Descriptive } \\
\text { Statistics } \\
M(S D)\end{array}$} & \multirow[t]{2}{*}{$\alpha$} & \multicolumn{5}{|c|}{ Pearson's Correlations } \\
\hline & & & 1 & 2 & 3 & 4 & 5 \\
\hline \multicolumn{8}{|c|}{ Study 2 (U.S.) } \\
\hline 1. Honor Values Scale & $4.76(0.86)$ & .89 & 1.00 & & & & \\
\hline 2. Government Distrust & $4.82(1.30)$ & .84 & .06 & 1.00 & & & \\
\hline 3. Self-Reliance & $4.58(1.68)$ & .94 & $.26^{* * *}$ & $.25^{* * *}$ & 1.00 & & \\
\hline 4. Independent Action & $4.82(1.28)$ & .87 & $.25^{* * *}$ & $.38^{* * *}$ & $.56^{* * *}$ & 1.00 & \\
\hline 5. Adherence to & $6.12(1.15)$ & .89 & -.02 & $-.08^{*}$ & $-.24^{* * *}$ & $-.29^{* * *}$ & 1.00 \\
\hline Guidelines & & & & & & & \\
\hline & $M(S D)$ & $\alpha$ & 1 & 2 & 3 & 4 & 5 \\
\hline \multicolumn{8}{|c|}{ Study 3 (Iran) } \\
\hline 1. Honor Values Scale & $5.11(0.77)$ & .87 & 1.00 & & & & \\
\hline 2. Government Distrust & $5.38(1.33)$ & .89 & $-.16^{*}$ & 1.00 & & & \\
\hline 3. Self-Reliance & $2.83(1.38)$ & .91 & .03 & $.16^{*}$ & 1.00 & & \\
\hline 4. Independent Action & $4.61(1.25)$ & .84 & .06 & $.57^{* * *}$ & $.39^{* * *}$ & 1.00 & \\
\hline $\begin{array}{l}\text { 5. Adherence to } \\
\text { Guidelines }\end{array}$ & $6.23(0.68)$ & .72 & $.18^{* *}$ & -.13 & $-.29^{* * *}$ & -.13 & 1.00 \\
\hline
\end{tabular}


$* p<.05, * * p<.01, * * * p<.001$

\subsubsection{Results}

3.2.2.1. Preliminary Analysis. We conducted confirmatory factor analyses and found that our items loaded onto our constructs (self-reliance, independent action, government distrust, and public health adherence), as presented in Supplemental Materials. Unexpectedly, we also found subscales in the HVS: one corresponding to protection of reputation and another corresponding to honorable conduct. Following our pre-registration, we report analyses with the overall HVS score in this paper, but we also present analyses using the subscales in Supplemental Materials. Generally, the two subscale scores share similar patterns of results as the overall score.

For exploratory purposes, we used independent samples t-tests to look for within-country variation on our 5 key variables (honor, government distrust, self-reliance, public health adherence, and independent action). We found greater endorsement of self-reliance in the U.S. South (defined by Cohen et al., 1996), as compared with the rest of the U.S, $t(409.35)=3.16, p=$ .002 , Cohen's $d=0.27$, though we found no difference between regions that voted Republican as compared to those that voted Democratic in the 2004, 2008, 2012, and 2016 Presidential elections. We present detailed results from these t-tests and explore regional differences further in Supplemental Materials. Our pattern of results generally did not differ between southern and non-southern states.

3.2.2.2. H1: Honor is Associated with Self-Reliance. We used linear regression to predict self-reliance from honor values (Table 5). Consistent with $\mathrm{H} 1$ and Study 1 results, participants who cared more about honor values showed greater preference for self-reliance, $\beta=$ $0.11, p=.002$ 
honor, $\beta=0.13,95 \%$ CI $[0.09,0.18]$ (bootstrapped 5000 times).

\section{Figure 7}

Study 2 (H2): Self-Reliance as Mediator Between Honor and Independent Action

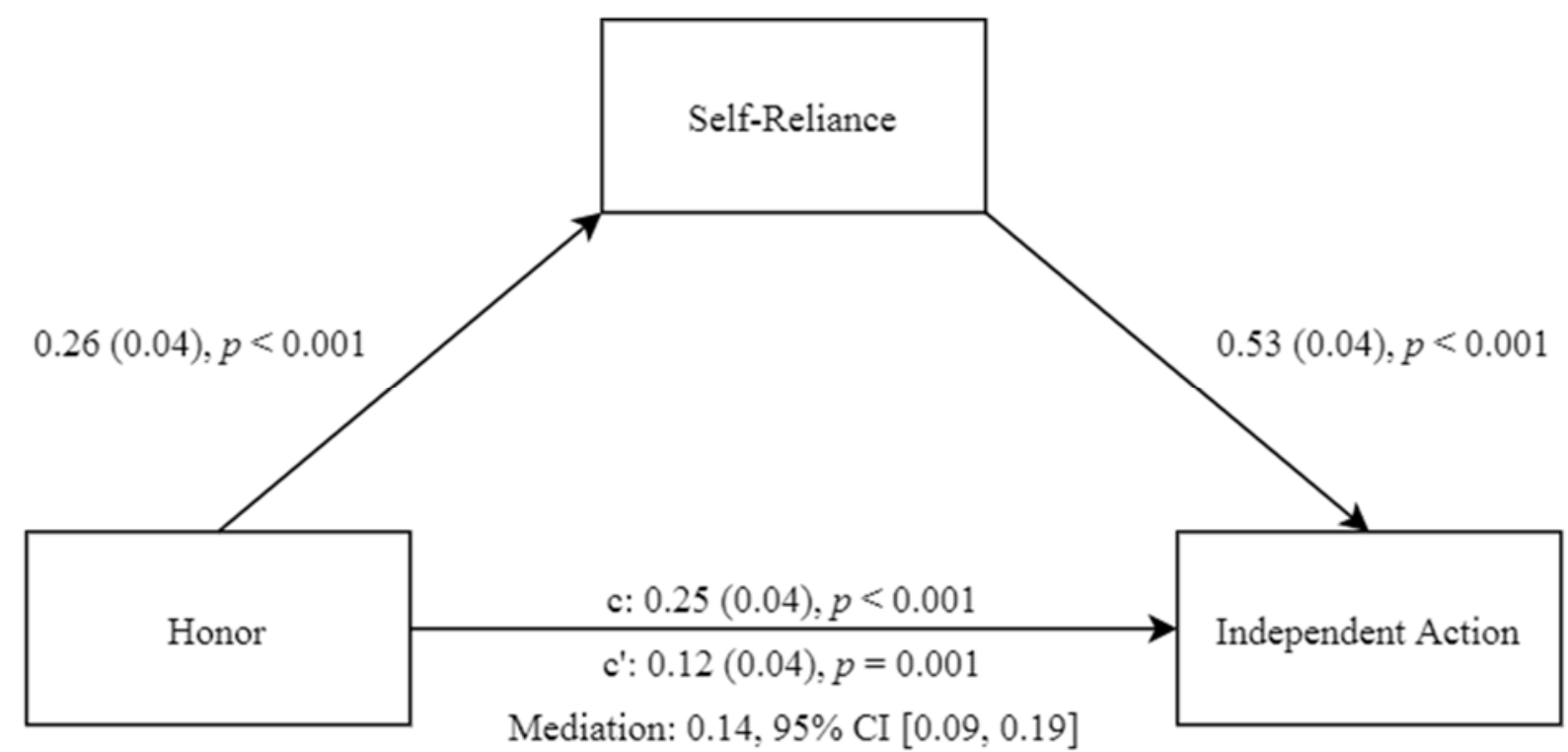

Note. Values inside the parentheses indicate standard errors.

\subsubsection{H3: Government Distrust Moderates the Relationship between Honor and}

Self-Reliance. To test H3, we ran a linear regression. As detailed in Table 5, our results did not support H3; government distrust did not significantly moderate the relationship between selfreliance and honor, $\beta=-0.05, p=.218$. We therefore did not proceed to conduct a moderated mediation analysis.

\subsubsection{H4: Self-Reliance Mediates the Relationship between Honor and Public}

Health Adherence. As in Study 1, we found a negative correlation between adherence to public health guidelines and self-reliance, $r=-.24, p<.001$, and no significant association between honor and adherence to guidelines, $r=-.02, p=.640$. We ran a mediation model with paths drawn from honor to self-reliance to public health adherence and found that self-reliance 
significantly mediated the relationship between honor and public health adherence, $\beta=-0.07$, 95\% CI [-0.09, -0.04] (bootstrapped 5000 times; see Figure 8). People who cared more about honor showed greater preference for self-reliance, and this preference in turn was associated with lower willingness to adhere to public health guidelines. An alternate model with paths from honor to adherence to self-reliance revealed no significant indirect effect of honor, $\beta=0.00,95 \%$ CI $[-0.01,0.02]$ (bootstrapped 5000 times). Since government distrust did not moderate the relationship between honor and self-reliance, we did not proceed with a moderated mediation model.

\section{Figure 8}

Study 2 (H4): Self-Reliance as Mediator Between Honor and Adherence

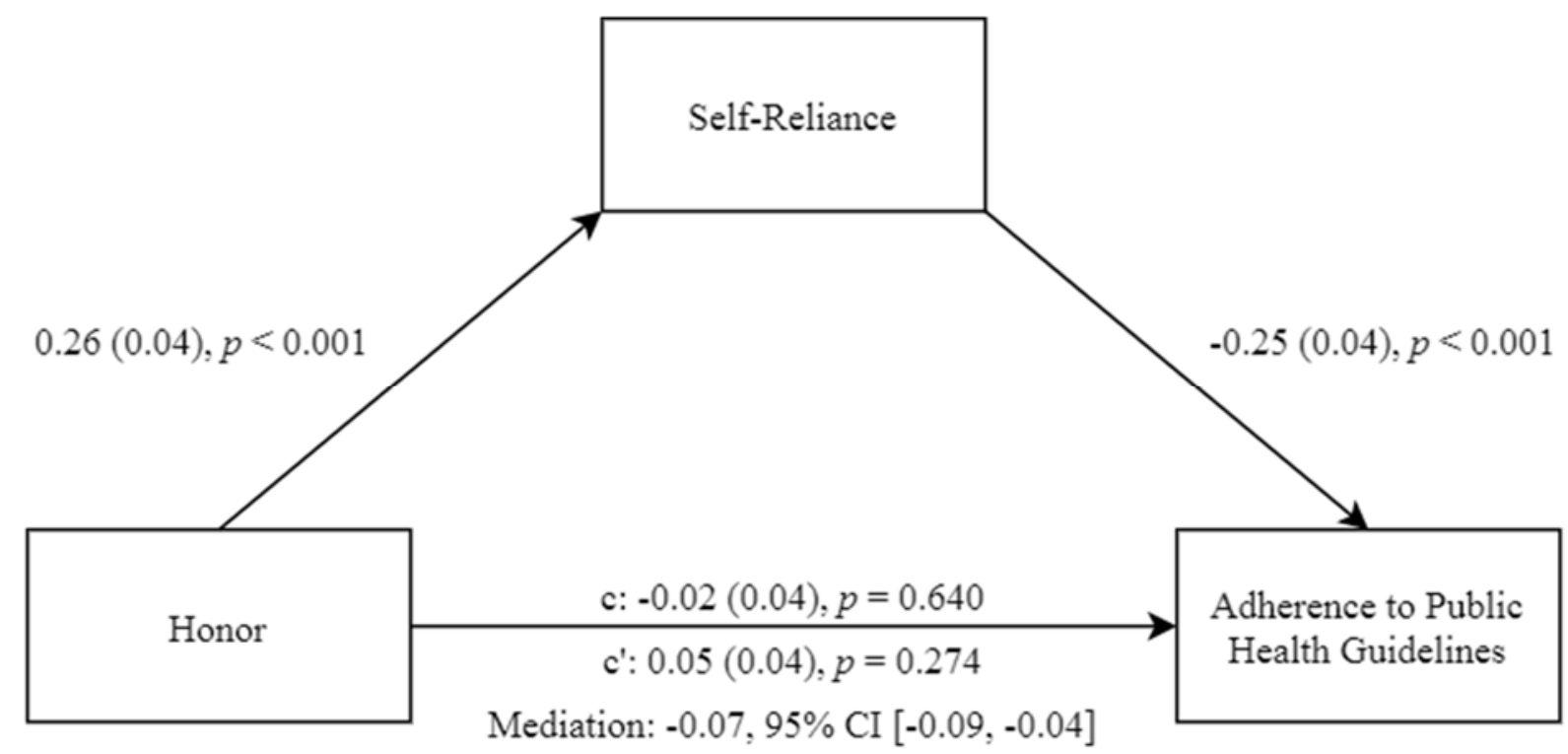

Note. Values inside the parentheses indicate standard errors.

\subsubsection{Discussion}

We predicted that people who care more about honor would be more willing to take 
independent action and less willing to follow government guidelines because they would prefer to be self-reliant. The pattern of effects generally supports our predictions. As in Study 1, the indirect effect of the alternate model for $\mathrm{H} 2$, the predicted mediation of honor and independent action by self-reliance, was significant, so we cannot rule out alternate explanations.

Study 2 participants showed similar patterns of responding to Study 1 participants. Hence, empirical support for our predictions was stable across data collected at two different periods during the COVID-19 pandemic. However, we did not find stable evidence for H3, the predicted interaction effect of honor and government distrust on self-reliance. We found moderation by government distrust among Americans in Study 1 but not in Study 2. This instability may be due to differences between May 2020 and September 2020, the time points of our Study 1 and Study 2 data collection. Specifically, we asked about specific issues such as protecting supply lines that may have become less relevant or salient by September 2020. Supply lines were a key concern given shortages of medical equipment in May, but by September, these shortages were no longer routinely discussed in the media. Many respondents may have assumed that they no longer existed.

\subsection{Study 3}

In Study 3, we examined whether honor has similar relationships to self-reliance and independent action in Iran as it does in the U.S.

\subsubsection{Methods}

We pre-registered Study 3 (https://aspredicted.org/blind.php? $\mathrm{x}=\mathrm{vb} 6 \mathrm{nv5}$ ) on AsPredicted.org.

3.3.1.1. Participants. We conducted a power analysis for recruitment of the Iranian sample based on key findings from the Study 2 sample. Based on an a priori power analysis in 
MedPower (Kenny, 2017) to detect the mediating role of self-reliance in the relationship between honor and independent action (specifying standardized coefficients 0.253 for path $a, 0.532$ for path $b$, and 0.118 for path $c^{\prime}$ ), aiming for an alpha of 0.05 , we needed 158 participants to find an indirect effect at $90 \%$ power. We exceeded our goal as we collected data in conjunction with another study, recruiting 201 Iranian participants online through social media advertisements on Telegram from the second to the last week of November 2020. Inclusion criteria were being of Iranian nationality, 18 or older, and speaking Farsi as a first language. No one was excluded from the analyses. See Table 1 for sample description.

3.3.1.2. Measures and Procedure. All items were administered through Google Forms. We kept the HVS, independent action scale, public health adherence scale, and self-reliance scale constant from Study 2. We detail descriptive statistics, internal consistency coefficients, and correlations among the study measures in Table 4. Order of measures and additional measures included for exploratory and secondary analyses are detailed in Supplemental Materials.

3.3.1.2.1. Government Distrust. Since the civil liberties item showed poor fit with the government distrust scale in Study 2, we did not administer it in Study 3.

3.3.1.2.2. Translation and Cultural Appropriateness. We administered the questionnaires in Farsi. We used Atari and colleagues' (2020) Farsi translation of the HVS. We translated the other measures to Farsi and back-translated them to English using the standard back-translation technique (Brislin, 1970). One of the co-authors resolved discrepancies between the two versions, as well as small linguistic and semantic issues in translation. We ensured readability, clarity, and fluency in Farsi.

For cultural appropriateness, we changed the political orientation item to a binary 
question ("left-leaning", "right-leaning") and dropped the attention-check and race-ethnicity items. We also replaced references to the $\mathrm{CDC}$ with the relevant Iranian government organization (the Ministry of Health and Medical Education).

To address concerns that our self-reliance items might be understood differently in Iran than in the U.S., we conducted semi-structured cognitive interviewing with a separate sample of 4 Iranians. Participants understood our Farsi self-reliance items as depending on their own beliefs and ideas, matching our intended meaning. We also conducted measurement invariance analyses for our key variables, reported in Supplemental Materials.

\subsubsection{Results}

3.3.2.1. Preliminary Analysis. We conducted confirmatory factor analyses and found that our items loaded onto our constructs (self-reliance, independent action, government distrust, and public health adherence), as presented in Supplemental Materials.

To examine between-country variations, we investigated potential differences in endorsement of each construct between Iran (Study 3) and the U.S. (Study 2; see Figure 9 for graphic comparisons). We found three significant cross-cultural differences. First, as expected, Iranians endorsed honor more strongly than Americans, Welch-corrected $t(382.31)=5.42, p<$ .001 , Cohen's $d=0.42$. Second, Iranians distrusted government more strongly than Americans, Welch-corrected $t(340.20)=5.18, p<.001$, Cohen's $d=0.43$. Third, Iranians showed lower preference for self-reliance than Americans, Welsh-corrected $t(419.61)=14.68, p<.001$, Cohen's $d=1.09$.

\section{Figure 9}

Mean Endorsement of Government Distrust, Honor, Self-Reliance, Independent Action, and Adherence to Guidelines by Country 


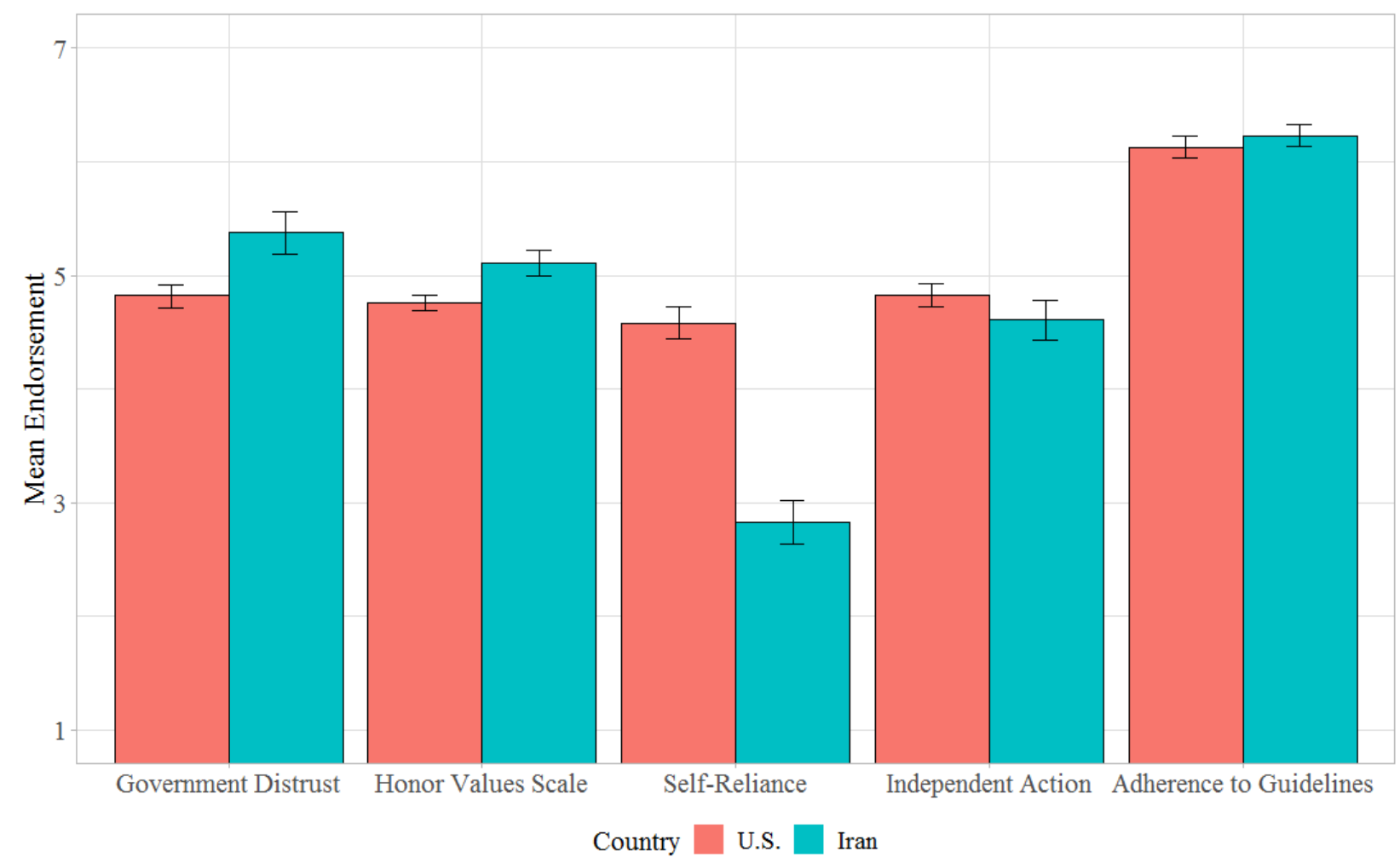

Note. Error bars indicate 95\% confidence intervals.

3.2.2.2. H1: Honor is Associated with Self-Reliance. We used linear regression to predict self-reliance from honor values (Table 6). Iranians who cared more about honor values did not show more or less preference for self-reliance, $\beta=0.03, p=.692$.

\section{Table 6}

Study 3 (H1, H3): Results of Linear Regressions Predicting Self-Reliance

\begin{tabular}{|c|c|c|c|c|c|c|c|c|}
\hline \multirow[t]{2}{*}{ Variable } & \multicolumn{8}{|c|}{ Statistics } \\
\hline & $\begin{array}{c}\beta \\
95 \% \mathrm{CI} \\
{[\mathrm{LL}, \mathrm{UL}]}\end{array}$ & $S E$ & $t$ & $p$ & $\begin{array}{l}\text { Adjusted } \\
\text { partial } R^{2}\end{array}$ & $F$ & $d f$ & $\begin{array}{c}\text { Adjusted } \\
R^{2}\end{array}$ \\
\hline \multicolumn{9}{|c|}{ Model H1 } \\
\hline Honor Values & $\begin{array}{c}0.03 \\
{[-0.11,0.17]}\end{array}$ & 0.07 & 0.40 & .692 & 0.00 & 0.16 & 199 & 0.00 \\
\hline \multicolumn{9}{|c|}{ Model H3 } \\
\hline Honor Values & $\begin{array}{c}0.05 \\
{[-0.09,0.19]}\end{array}$ & 0.07 & 0.75 & .452 & 0.00 & 2.78 & 197 & 0.03 \\
\hline Government Distrust & $\begin{array}{c}0.21 \\
{[0.06,0.35]}\end{array}$ & 0.07 & 2.76 & .006 & 0.03 & & & \\
\hline
\end{tabular}


Honor Values $\times \quad \begin{array}{llllll} & -0.10 & 0.06 & 1.61 & .108 & 0.01\end{array}$

Government Distrust $\quad[-0.22,0.02]$

Note. H1: Honor values and self-reliance. H3: Moderation of honor values by government distrust in predicting self-reliance.

\subsubsection{H2: Self-Reliance Mediates the Relationship between Honor and}

Independent Action. As detailed in Table 4, independent action correlated with self-reliance, $r$ $=.39, p<.001$, but not with honor concerns, $r=.06, p=.428$. Moreover, honor concerns did not correlate with self-reliance, $r=.03, p=.692$. Therefore, self-reliance did not mediate honor and independent action (Figure 10), $\beta=0.01,95 \%$ CI [-0.05, 0.07] (bootstrapped 5000 times), mediation effect $R^{2}=0.001$ (for calculation of mediation effect $R^{2}$, see Fairchild et al., 2009). Our sample was mostly (85.1\%) politically left-leaning so we added political orientation as a control. Adding this control, and the interaction of political orientation and honor, did not change the pattern of results (see Supplemental Materials).

\section{Figure 10}

Study 3 (H2): Self-Reliance as Mediator Between Honor and Independent Action

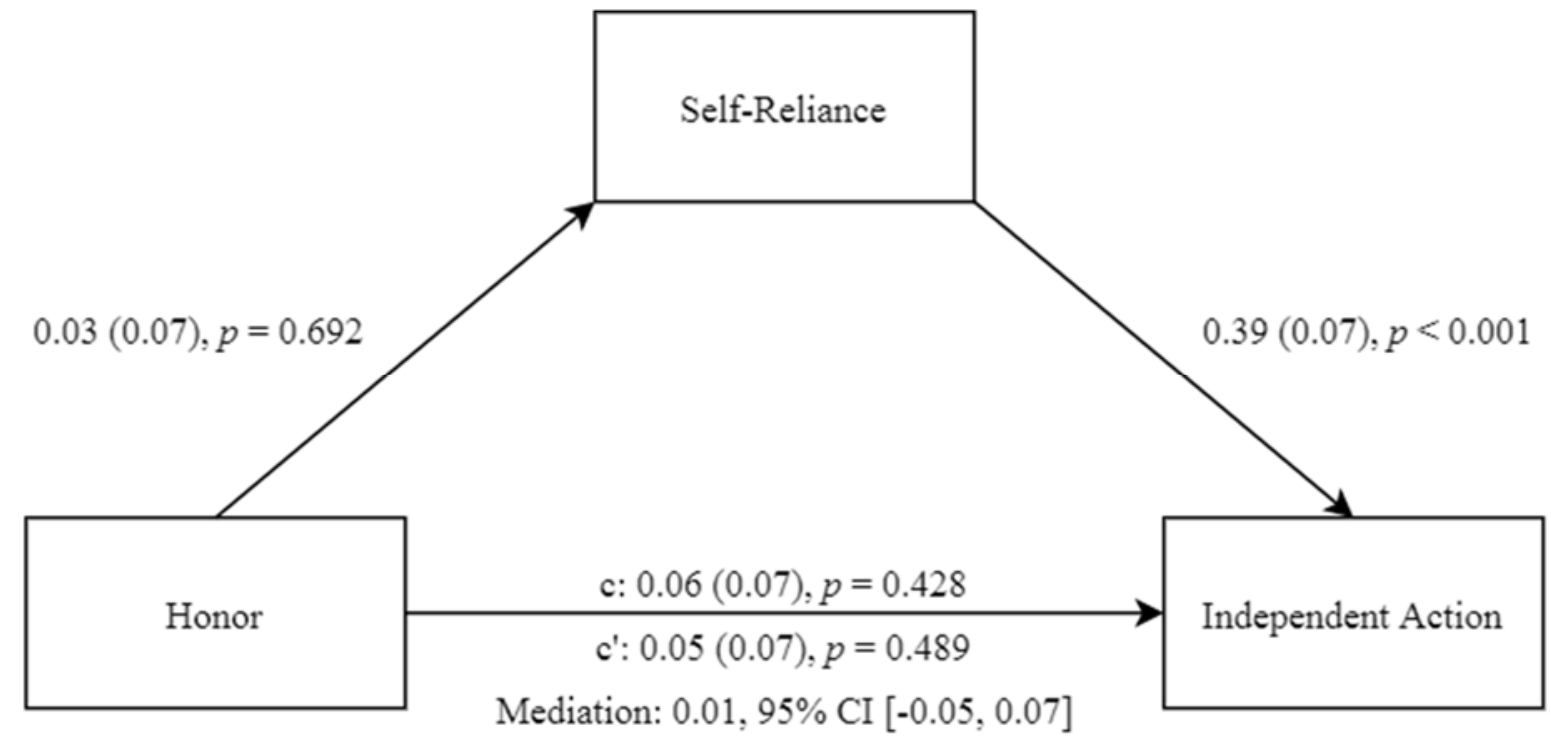


Note. Values inside the parentheses indicate standard errors.

\subsubsection{H3: Government Distrust Moderates the Relationship between Honor and}

Self-Reliance. To test H3, we ran a linear regression. Our results did not support H3 (Table 6); government distrust did not significantly moderate the relationship between self-reliance and honor, $\beta=-0.10, p=.108$. We therefore did not proceed to conduct a moderated mediation analysis.

\subsubsection{H4: Self-Reliance Mediates the Relationship between Honor and Public}

Health Adherence. As in Studies 1 and 2, we found a negative correlation between adherence to public health guidelines and self-reliance, $r=-.29, p<.001$. However, we found a significant, though low, positive association between honor and adherence to guidelines, $r=.18, p=.010$. Since honor did not correlate with self-reliance, we found that self-reliance did not mediate the relationship between honor and public health adherence, $\beta=-0.01,95 \%$ CI $[-0.05,0.03]$ (bootstrapped 5000 times; see Figure 11). Because government distrust did not moderate the relationship between honor and self-reliance, we did not proceed with a moderated mediation model.

\section{Figure 11}

Study 3 (H4): Self-Reliance as Mediator Between Honor and Adherence 


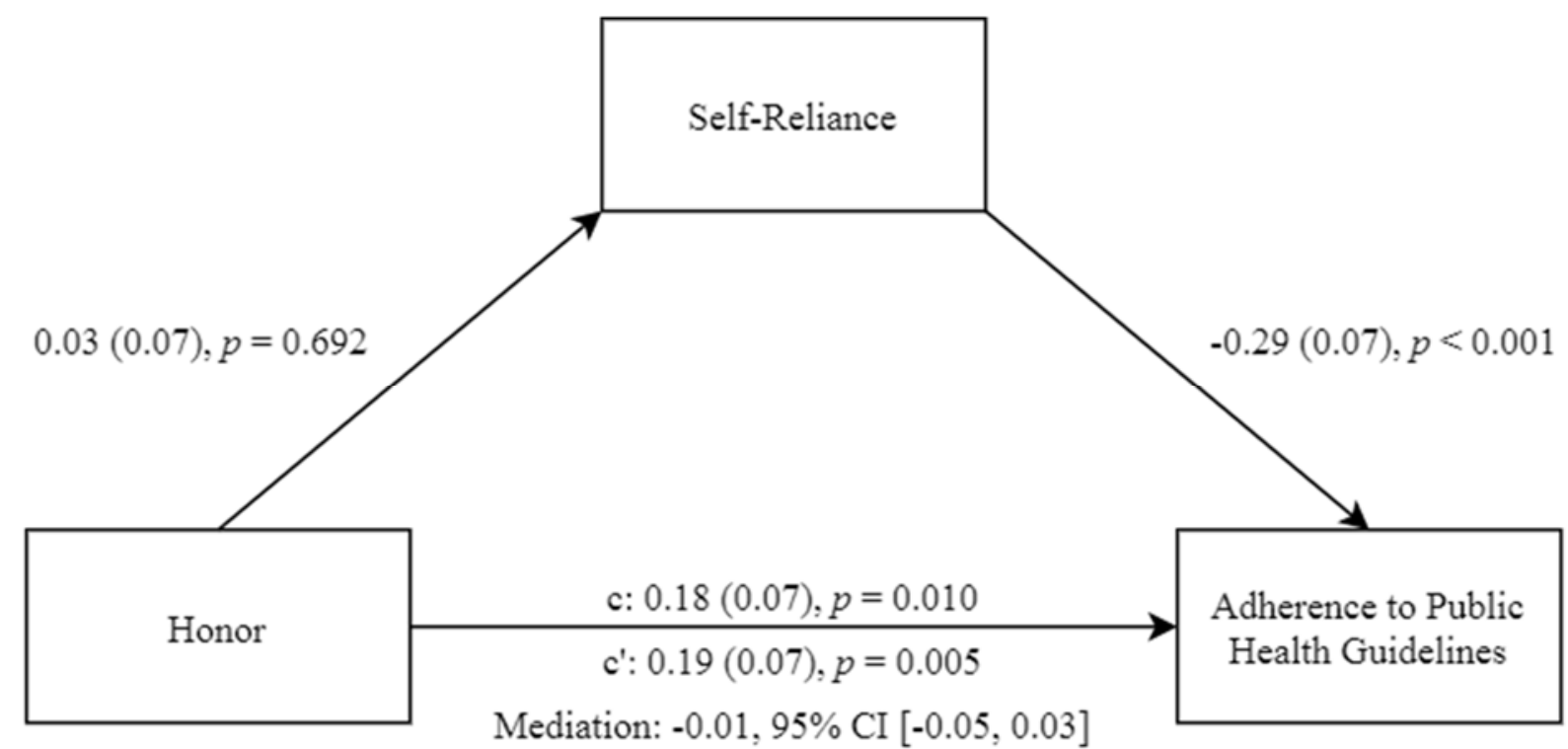

Note. Values inside the parentheses indicate standard errors.

\subsubsection{Discussion}

Iranians (Study 3) responded differently from Americans (Studies 1 and 2). Iranians who expressed higher endorsement of honor values did not prefer self-reliance and did not act more independently of government, in contrast to $\mathrm{H} 1$ and $\mathrm{H} 2$ predictions. We found no evidence for an H3 interaction. Contrary to our H4 prediction, Iranians who endorsed honor values adhered more closely to public health guidelines. Moreover, in Iran, higher endorsement of honor values was associated with less distrust of government, unlike in the U.S. As in Study 1, we found a small, significant correlation between self-reliance and government distrust. Considering the low endorsement of self-reliance in Iran, results suggest that Iranians may be reluctant to rely on themselves, and distrust of government is not enough to motivate self-reliance.

Online recruitment allowed us to access participants in Iran but also resulted in a primarily left-leaning sample. While future studies can focus more closely on differences in political orientation in Iran, our pattern of results did not differ between the left-leaning and 
right-leaning participants.

\section{General Discussion}

In three studies, we focused on the relationship between honor mindset, independent action, and adherence to public health guidelines during the pandemic. Honor is a cultural mindset which evolved as part of human culture; it is focused on preserving safety and wellbeing by regulating relationships through protecting reputation (Oyserman, 2011; 2017). It is triggered when central authorities such as governmental institutions fail to protect social order and regulate the flow of scarce but needed resources (Nowak et al., 2016; Uskul \& Cross, 2020). One way to deter threats to self, family and in-groups in these situations is to show that one can fend for oneself (Leung \& Cohen, 2011). This implies that honor may be associated with selfreliance, and in turn, increased independent action and decreased adherence to public health guidelines, especially among individuals who distrust the government. We tested these predictions in the U.S. and Iran.

Our analyses showed that Americans higher in honor endorsement were more willing to be self-reliant, taking more independent action and adhering less to COVID-19 public health guidelines (Studies 1 and 2). We did not find convincing evidence for these associations in our Iranian sample (Study 3). Our prediction that government distrust would interact with honor to predict self-reliance was supported in Study 1, but not Study 2.

\subsection{Theoretical Implications}

Our results advance the literature in two ways. First, we provide initial evidence that honor may influence how people react to government instructions and policy decisions under threat. While researchers generally discuss honor culture in terms of its historically opposing relationship with government institutions (e.g., Nowak et al., 2016; Shackelford, 2005), the 
extent to which honor promotes anti-government orientations in the present day is unclear. We expand on prior studies linking masculine honor with opposition to pandemic rules (Schiffer et al., 2021) by showing that U.S. adults who value honor act independently of government and adhere less to public health guidelines because they prefer to rely on themselves. Since we used gender-neutral measures of honor, our findings are not limited to masculine honor. Since we measured both self-reliance and adherence to guidelines, our findings have clearer implications for interventions targeting communities with strong honor values - public health messages and other persuasive tools should be tailored to the self-reliant attitudes of honor-minded individuals.

Moreover, while new evidence indicates that intentions to engage in governmentprescribed health behaviors may not be related to country-level number of infections (Pagliaro et al., 2021), the link between political trust and pandemic-related health outcomes (Devine et al., 2021; Pagliaro et al., 2021) suggests that views about dependence on government may influence the progression of the pandemic. The pandemic effort may benefit from interventions targeting communities that devalue dependence on government, which, at least in the U.S., includes communities that follow a culture of honor.

Second, our analyses suggest that the way people express honor may depend on contextual factors within a given society. Distinct patterns of results between the U.S. and Iranian samples indicate that honor does not share the same relationship with self-reliance in Iran as it does in the U.S. This sheds light on the nature of honor culture by supplementing prior theorizing about honor and self-reliance. By showing that honor relates to self-reliance and cooperation differently in the U.S. and Iran, our work demonstrates that country-level factors can limit the influence of honor on attitudes and responses toward government. Our findings are consistent with culture-as-situated-cognition theory (Oyserman, 2011) - even when people 
endorse the same honor values, they may apply these values differently depending on how their choices are framed. While more work is needed to clarify contextual factors that shape honor responses, we outline two plausible accounts below.

\subsubsection{Differential Expression of Honor Across Cultures}

Generally, people with honor concerns are motivated to maintain social image and reputation, and they do so by adhering to social norms about what it means to have a good reputation. This implies that the strategies people use for maintaining reputation depend on their link to shared values. For example, if a society values self-reliance, actions that demonstrate selfreliance in that society should be useful for maintaining one's reputation. American individualism promotes self-reliance as a sacred value and places it in opposition to government intervention (Bazzi et al., 2020). To maintain their reputation, Americans might show that they can look out for themselves without assistance from others, including their federal or state government. Because of this individualistic emphasis on self-reliance, Americans perceive selfreliance as honorable. Because they believe self-reliance to be antithetical to government assistance, Americans with honor concerns will ignore government-issued pandemic directives. We found both of these outcomes in our studies. In contrast, Iran may not share these values of self-reliance, evidenced by a substantially lower endorsement of self-reliance in Study 3. Iranian honor is strongly oriented toward kin (Atari et al., 2020) and Iranian culture is substantially less individualistic (Hofstede et al., 2010). As we saw in Study 3, without a shared sense that selfreliance is admirable, Iranians with honor concerns showed no preference for self-reliance. The implication is that a preference for self-reliance is not inherent to honor. Consistent with cultureas-situated-cognition theory, this view suggests that shared societal beliefs determine which values and behaviors are relevant to honor. 


\subsubsection{Viability of Self-Reliance}

A second possibility highlights the objective viability of self-reliance. International sanctions (imposed by the U.S.) against Iran have led to a deep economic recession (Murphy et al., 2020) and a steep increase in the cost of basic goods (Kokabisaghi, 2018). U.S. sanctions obstructed Iran from obtaining COVID-19 vaccines later in the pandemic when these became available (Reuters Staff, 2020), while poor economic conditions in Iran impede access to healthcare (Aloosh et al., 2019) and COVID-19 treatment (Murphy et al., 2020). Self-reliance may not be a viable option for people who lack access to healthcare and consumer goods. Instead, Iranians may rely on their communities for mutual aid and cooperation. Under these conditions, self-reliance conflicts with the protective function of honor, explaining why Iranians reported a lower preference for self-reliance and why honor did not relate to self-reliance. Also consistent with culture-as-situated-cognition theory, this view suggests that situational constraints and affordances determine which values and behaviors are relevant to honor.

Both accounts suggest that prior theorization about honor may be too rooted in an American or Western perspective. This perspective treats preference for self-reliance as a core component of honor culture when the link between self-reliance and honor may be actually tied to the traditions and histories of specific societies. Our findings add to the emerging literature on the cultural evolution of honor by suggesting that the effects of honor on behavior in the present time may depend on context in complex ways.

\subsection{Limitations}

Limitations of the present research are worth noting. A key limitation is that our mediation models are based on cross-sectional data and cannot demonstrate causality. Although these results are consistent with our theory-driven predictions, we cannot rule out alternative 
causal explanations. Indeed, our results show that an alternate model with paths drawn from honor values to independent action to self-reliance may also be possible. For Study 1, the indirect effect of honor in the alternate model was smaller than the effect in our predicted model, but for Study 2 it was similar to the effect in our predicted model. Moreover, reverse mediation testing is often not sufficient for determining the direction of mediation (Lemmer \& Gollwitzer, 2017). Using cross-sectional data for mediation analysis also leads to biased estimates even in highly controlled conditions (Fiedler, Schott, \& Meiser, 2011). Therefore, we encourage future work to test these mediation models using longitudinal or experimental mediation designs. Moreover, while we tested the stability of our findings over time in the U.S., the ever-changing nature of the pandemic, efficacy of government response, and their effects on public trust in government make replication in Iran vital.

\subsubsection{Role of Face and Other Aspects of Culture}

We focused primarily on honor culture in our studies. Future studies could examine other aspects of culture, including individualism, collectivism, and face. We expected that honor culture would be embedded within other aspects of culture, especially, as we described above, individualism and collectivism. Regarding face culture, researchers associate face culture with reputational concerns for humility and harmony rather than the honor-focused reputational concerns for protecting and preserving oneself and family (Leung \& Cohen, 2011; Smith et al., 2021). We made no predictions on effects of face culture and did not attempt to measure face culture. Though the Honor Values Scale we used includes the word "face" in some items to refer to the reputational concerns central to honor, as expected and detailed in our Supplemental Materials, these items loaded onto the same factor as other honor items. Hence, we cannot draw any conclusions about the role of face culture in cooperation with government and this remains a 
possible endeavor for future studies.

\subsubsection{Control Variables}

We controlled for gender and political orientation, two variables that might be potentially relevant to honor (Guerra et al., 2013) and cooperation with government (Falk \& Hermle, 2018). We looked for but did not find effects of country region either in terms of geography or in terms of the voting patterns for Republican or Democratic nominees. Our effects were small and hence future studies could examine other factors that might also matter, including years of formal education, scores on tests of health literacy, and access to mis- or disinformation. We did ask people in Study 1 if they were aware of the then-current CDC guidelines, and most were, implying that awareness alone is not the active ingredient in our effects.

\section{Conclusion}

In three studies we demonstrated that cultural factors shape how strongly people adhere to government directives during the COVID-19 pandemic. Americans, but not Iranians, concerned with honor tend to rely on themselves and act independently of government recommendations during the COVID-19 pandemic. Our results have theoretical and practical implications. Theoretically, our findings suggest that situational factors determine whether honor motivates people to rely on themselves over their government. These situational factors can allow us to predict when honor-minded people will cooperate with government directives. From a practical perspective, it may be helpful to consider the prevalence of honor values when requesting cooperation from a community. To be effective, public health guidelines need to be framed as complementary to honor values. 


\section{References}

Agler, R., \& De Boeck, P. (2017). On the interpretation and use of mediation: Multiple perspectives on mediation analysis. Frontiers in Psychology, 8, 1984. https://doi.org/10.3389/fpsyg.2017.01984

Alagoz, O., Sethi, A. K., Patterson, B. W., Churpek, M., \& Safdar, N. (2020). Effect of timing of and adherence to social distancing measures on COVID-19 burden in the United States: A simulation modeling approach. Annals of Internal Medicine. https://doi.org/10.7326/M20-4096

Aloosh, M., Salavati, A., \& Aloosh, A. (2019). Economic sanctions threaten population health: The case of Iran. Public Health, 169, 10-13. https://doi.org/10.1016/j.puhe.2019.01.006

Ashayeri, T., \& Ajami, M. (2015). The sociology of social cultural beliefs affecting the reputational homicides. Criminal Intelligence Researches, 10(1), 29-54.

Atari, M., Graham, J., \& Dehghani, M. (2020). Foundations of morality in Iran. Evolution and Human Behavior, 41(5), 367-384. https://doi.org/10.1016/j.evolhumbehav.2020.07.014

Atari, M., Graham, J., \& Dehghani, M. (2021). Toward a cumulative science of non-WEIRD morality: A reply to Rezvani Nejad et al. Evolution and Human Behavior. https://doi.org/10.1016/j.evolhumbehav.2021.02.006

Baddeley, M. (2020). Hoarding in the age of COVID-19. Journal of Behavioral Economics for Policy, 4(S), 69-75.

Bazzi, S., Fiszbein, M., \& Gebresilasse, M. (2020). Frontier culture: The roots and persistence of “rugged individualism" in the United States. Econometrica, 88(6), 2329-2368. https://doi.org/10.3982/ECTA16484 
Brehm, J. W. (1989). Psychological reactance: Theory and applications. Advances in Consumer Research, 16, 72-75.

Brislin, R. W. (1970). Back-translation for cross-cultural research. Journal of Cross-Cultural Psychology, 1(3), 185-216. https://doi.org/10.1177/135910457000100301

Calvillo, D. P., Ross, B. J., Garcia, R. J., Smelter, T. J., \& Rutchick, A. M. (2020). Political ideology predicts perceptions of the threat of covid-19 (and susceptibility to fake news about it). Social Psychological and Personality Science, 11(8), 1119-1128. https://doi.org/10.1177/1948550620940539

Cao, Y., Enke, B., Falk, A., Giuliano, P., \& Nunn, N. (2021). Herding, Warfare, and a Culture of Honor: Global Evidence (No. w29250). National Bureau of Economic Research.

Chan E. Y. (2020). Moral foundations underlying behavioral compliance during the COVID-19 pandemic. Personality and Individual Differences, 110463. https://doi.org/10.1016/j.paid.2020.110463

Chan, H. F., Brumpton, M., Macintyre, A., Arapoc, J., Savage, D. A., Skali, A., Stadelmann, D., \& Torgler, B. (2020). How confidence in health care systems affects mobility and compliance during the COVID-19 pandemic. PLoS One, 15(10), e0240644. https://doi.org/10.1371/journal.pone.0240644

Chen, S. X., Ng, J. C. K., Hui, B. P. H., Au, A. K. Y., Wu, W. C. H., Lam, B. C. P., Mak, W. W. S., \& Liu, J. H. (2021). Dual impacts of coronavirus anxiety on mental health in 35 societies. Scientific Reports, 11(1). https://doi.org/10.1038/s41598-021-87771-1.

Civai, C., Caserotti, M., Carrus, E., Huijsmans, I., \& Rubaltelli, E. (2021, March 31). Perceived scarcity and cooperation contextualized to the COVID-19 pandemic. https://doi.org/10.31234/osf.io/zu2a3 
Cohen, D., \& Nisbett, R. E. (1997). Field experiments examining the culture of honor: The role of institutions in perpetuating norms about violence. Personality and Social Psychology Bulletin, 23(11), 1188-1199. https://doi.org/10.1177/01461672972311006

Cohen, D., Nisbett, R. E., Bowdle, B. F., \& Schwarz, N. (1996). Insult, aggression, and the southern culture of honor: An "experimental ethnography”. Journal of Personality and Social Psychology, 70(5), 945-960. https://doi.org/10.1037/0022-3514.70.5.945

Cohen, J. (1988). Statistical power analysis for the behavioral sciences (2nd ed.). Erlbaum.

Cross, S. E., Uskul, A. K., Gerçek-Swing, B., Sunbay, Z., Alözkan, C., Günsoy, C., Bilge, A., \& Karakitapoğlu-Aygün, Z. (2014). Cultural prototypes and dimensions of honor. Personality and Social Psychology Bulletin, 40(2), 232-249. https://doi.org/10.1177/0146167213510323

Deslatte, A. (2020). The erosion of trust during a global pandemic and how public administrators should counter it. The American Review of Public Administration, 50(6-7), 489-496. https://doi.org/10.1177/0275074020941676

Devine, D., Gaskell, J., Jennings, W., \& Stoker, G. (2020). Trust and the coronavirus pandemic: What are the consequences of and for trust? An early review of the literature. Political Studies Review, 19(2), 274-285. https://doi.org/10.1177/1478929920948684

Dong, E., Du, H., \& Gardner, L. (2020). An interactive web-based dashboard to track COVID-19 in real time. The Lancet. Infectious Diseases, 20(5), 533-534. https://doi.org/10.1016/S1473-3099(20)30120-1

Eisinga, R., Te Grotenhuis, M., \& Pelzer, B. (2013). The reliability of a two-item scale: Pearson, Cronbach, or Spearman-Brown?. International Journal of Public Health, 58, 637-642. https://doi.org/10.1007/s00038-012-0416-3 
Fairchild, A. J., MacKinnon, D. P., Taborga, M. P., \& Taylor, A. B. (2009). R² effect-size measures for mediation analysis. Behavior Research Methods, 41(2), 486-498. https://doi.org/10.3758/BRM.41.2.486

Falk, A., \& Hermle, J. (2018). Relationship of gender differences in preferences to economic development and gender equality. Science, 362(6412). https://doi.org/10.1126/science.aas9899

Faul, F., Erdfelder, E., Buchner, A., \& Lang, A. G. (2009). Statistical power analyses using G*Power 3.1: Tests for correlation and regression analyses. Behavior Research Methods, 41, 1149-1160. https://doi.org/10.3758/BRM.41.4.1149

Fiedler, K., Schott, M., \& Meiser, T. (2011). What mediation analysis can (not) do. Journal of Experimental Social Psychology, 47(6), 1231-1236. https://doi.org/10.1016/j.jesp.2011.05.007

Fletcher, R., Kalogeropoulos, A., \& Nielsen, R. K. (2020). Trust in UK government and news media COVID-19 information down, concerns over misinformation from government and politicians up. Reuters Institute for the Study of Journalism. https://ssrn.com/abstract=3633002.

Flinkenflogel, N., Novin, S., van der Meulen, A., \& Krabbendam, L. (2020). Where to draw the line: Honor mindset increases retaliation in response to unfair behavior. Culture and Brain, 1-16. https://doi.org/10.1007/s40167-020-00093-3

Harris, K. (2020). Pandemic politics in Iran. Current History, 119(821), 338-342. https://doi.org/10.1525/curh.2020.119.821.338

Hofstede, G., Hofstede G. J., \& Minkov, M. (2010). Cultures and organizations: Software of the mind. Revised and Expanded 3rd Edition. New York: McGraw-Hill. 
Holland, S., \& Alper, A. (2020). 'Don't be afraid' of COVID, Trump says as he returns to White House that is stalked by illness. Reuters. https://www.reuters.com/article/healthcoronavirus-trump/dont-be-afraid-of-covid-trump-says-as-he-returns-to-white-house-thatis-stalked-by-illness-idUSKBN26Q0CU

Guerra, V. M., Giner-Sorolla, R., \& Vasiljevic, M. (2013). The importance of honor concerns across eight countries. Group Processes \& Intergroup Relations, 16(3), 298-318. https://doi.org/10.1177/1368430212463451

Haberman, M. (2020). Trump, head of government, leans into antigovernment message. The New York Times. https://www.nytimes.com/2020/04/20/us/politics/trumpcoronavirus.html

Islam, T., Pitafi, A. H., Arya, V., Wang, Y., Akhtar, N., Mubarik, S., \& Xiaobei, L. (2021). Panic buying in the COVID-19 pandemic: A multi-country examination. Journal of Retailing and Consumer Services, 59, 102357. https://doi.org/10.1016/j.jretconser.2020.102357

Johnson, T. (2020). "You want to be politically correct”: Donald Trump mocks reporter for leaving on his mask during press availability. Deadline. https://deadline.com/2020/05/coronavirus-donald-trump-masks-jeff-mason-1202943810/

Kenny, D. A. (2017, February). MedPower: An interactive tool for the estimation of power in tests of mediation [Computer software]. https://davidakenny.shinyapps.io/MedPower/.

Kokabisaghi, F. (2018). Assessment of the effects of economic sanctions on Iranians' right to health by using Human Rights Impact Assessment tool: A systematic review. International Journal of Health Policy and Management, 7(5), 374-393. https://doi.org/10.15171\%2Fijhpm.2017.147 
Lee, B. Y. (2021). Study claiming face masks harmful, increase $\mathrm{CO}_{2}$ for children is retracted. Forbes. https://www.forbes.com/sites/brucelee/2021/07/17/face-mask-study-says-co2increases-in-children-but-then-is-retracted/

Lemmer, G. \& Gollwitzer, M. (2017). The “true” indirect effect won't (always) stand up: When and why reverse mediation testing fails. Journal of Experimental Social Psychology, 69, 144-149. https://doi.org/10.1016/j.jesp.2016.05.002

Leung, A. K. Y., \& Cohen, D. (2011). Within-and between-culture variation: Individual differences and the cultural logics of honor, face, and dignity cultures. Journal of Personality and Social Psychology, 100(3), 507-526. https://doi.org/10.1037/a0022151

McElreath, R. (2003). Reputation and the evolution of conflict. Journal of Theoretical Biology, 220(3), 345-357. https://doi.org/10.1006/jtbi.2003.3166

Murphy, A., Abdi, Z., Harirchi, I., McKee, M., \& Ahmadnezhad, E. (2020). Economic sanctions and Iran's capacity to respond to COVID-19. The Lancet Public Health, 5(5), e254. https://doi.org/10.1016/S2468-2667(20)30083-9

Novin, S., \& Oyserman, D. (2016). Honor as cultural mindset: Activated honor mindset affects subsequent judgment and attention in mindset-congruent ways. Frontiers in Psychology, 7, 1921. https://doi.org/10.3389/fpsyg.2016.01921

Nowak, A., Gelfand, M. J., Borkowski, W., Cohen, D., \& Hernandez, I. (2016). The evolutionary basis of honor cultures. Psychological Science, 27(1), 12-24.

\section{https://doi.org/10.1177/0956797615602860}

Oyserman, D. (2011). Culture as situated cognition: Cultural mindsets, cultural fluency, and meaning making. European Review of Social Psychology, 22(1), 164-214. https://doi.org/10.1080/10463283.2011.627187 
Oyserman, D. (2017). Culture three ways: Culture and subcultures within countries. Annual Review of Psychology, 68, 435-463. https://doi.org/10.1146/annurev-psych-122414$\underline{033617}$

Pagliaro, S., Sacchi, S., Pacilli, M. G., Brambilla, M., Lionetti, F., Bettache, K., Bianchi, M., Biella, M., Bonnot, V., Boza, M., Butera, F., Ceylan-Batur, S., Chong, K., Chopoza, T., Crimston, C. R., Álvarez, B., Cuadrado, I., Ellemers, N., Formanowicz, M., ... \& Zubieta, E. (2021). Trust predicts COVID-19 prescribed and discretionary behavioral intentions in 23 countries. PLoS ONE, 16(3), e0248334. https://doi.org/10.1371/journal.pone.0248334

Razavi, P., Shaban-Azad, H., \& Srivastava, S. (2020). Gheirat as a complex emotional reaction to relational boundary violations. PsyArXiv. https://doi.org/10.31234/osf.io/8ev23

Reuters Staff (2020, November 13). Iran blames U.S. sanctions for vaccine payment problems. Reuters. https://www.reuters.com/article/us-health-coronavirus-iran-idUSKBN27T26H

Ritchie, H., Ortiz-Ospina, E., Beltekian, D., Mathieu, E., Hasell, J., Macdonald, B., Giattino, C., Appel, C., Rodés-Guirao, L., \& Roser, M. (2020). Coronavirus pandemic (COVID-19). OurWorldInData.org. https://ourworldindata.org/coronavirus

Rosenfeld, D. L., Balcetis, E., Bastian, B., Berkman, E. T., Bosson, J. K., Brannon, T. N., Burrow, A. L., Cameron, C. D., Chen, S., Cook, J. E., Crandall, C., Davidai, S., Dhont, K., Eastwick, P. W., Gaither, S. E., Gangestad, S. W., Gilovich, T., Gray, K., Haines, E. L., ... Tomiyama, A. J. (2021). Psychological science in the wake of COVID-19: Social, methodological, and meta-scientific considerations. Perspectives on Psychological Science. https://doi.org/10.31234/osf.io/6gjfm 
Schiffer, A. A., O'Dea, C. J., \& Saucier, D. A. (2021). Moral decision-making and support for safety procedures amid the COVID-19 pandemic. Personality and Individual Differences, 175, 110714. https://doi.org/10.1016/j.paid.2021.110714

Shackelford, T. K. (2005). An evolutionary psychological perspective on cultures of honor. Evolutionary Psychology, 3, 381-391. https://doi.org/10.1177/147470490500300126

Simonov, A., Sacher, S. K., Dubé, J. P. H., \& Biswas, S. (2020). The persuasive effect of FOX News: Non-compliance with social distancing during the COVID-19 pandemic (NBER Working Paper 27237). Cambridge, MA: National Bureau of Economic Research. https://doi.org/10.2139/ssrn.3600088

Smith, P. B., Easterbrook, M. J., Koc, Y., Lun, V. M.-C., Papastylianou, D., Grigoryan, L., Torres, C., Efremova, M., Hassan, B., Abbas, A., Ahmad, A. H., al-Bayati, A., Selim, H. A., Anderson, J., Cross, S. E., Delfino, G. I., Gamsakhurdia, V., Gavreliuc, A., Gavreliuc, D., ... Chobthamkit, P. (2021). Is an emphasis on dignity, honor and face more an attribute of individuals or of cultural groups?. Cross-Cultural Research, 55(2-3), 95-126. https://doi.org/10.1177\%2F1069397120979571

Uskul, A. K., \& Cross, S. E. (2020). Socio-ecological roots of cultures of honor. Current Opinion in Psychology, 32, 177-180. https://doi.org/10.1016/j.copsyc.2019.11.001

Uskul, A. K., Oyserman, D., \& Schwarz, N. (2010). Cultural emphasis on honor, modesty, or self-enhancement: Implications for the survey response process. In J. Harkness, M. Braun, B. Edwards, T. Johnson, L. Lyberg, P. Mohler, B. Pennell, \& T. Smith (Eds), Wiley series in survey methodology. Survey methods in multinational, multiregional, and multicultural contexts (p. 191-201). Wiley. https://doi.org/10.1002/9780470609927.ch11 
Vance, J. D. (2016). Hillbilly elegy: A memoir of a family and culture in crisis. HarperCollins. 